\title{
ZWEITER ABSCHNITT: 1858-1877 \\ Ausbau des Verlags \\ und Beginn der Spezialisierung
}

$\mathrm{M}$ an könnte vermuten, daß Springer seine Mittel und Kräf- Die >Neue Ära te, die nach dem Verkauf der Buchhandlung frei geworden waren, dem Ausbau seiner fachspezifisch orientierten Verlagsprogramme zugewandt hätte. Dies geschah zunächst jedoch nur in begrenztem Umfang. Eine grundlegende Änderung der politischen Situation in Preußen veranlaßte Springer vielmehr, sich wieder verstärkt mit politischen Schriften den Debatten des Tages zuzuwenden.

Im Oktober 1857 hatte Prinz Wilhelm die Vertretung seines erkrankten Bruders, König Friedrich Wilhelm IV., übernommen. Ein Jahr später wurde er Regent und am 2.1.1861, nach dem Tod des Bruders, als Wilhelm I. preußischer König. In den Revolutionstagen 1848/49 war er als >Kartätschenprinz< verrufen, denn unter seinem militärischen Oberbefehl waren die Aufstände in Baden und in der Pfalz niedergeworfen worden. Als preußischer Militärgouverneur im Rheinland und in Westfalen hatte er aber, angesichts der günstigen wirtschaftlichen Entwicklung in diesen Landen und eines damit einhergehenden Erstarkens bürgerlichen Selbstbewußtseins, die Notwendigkeit zum Ausgleich zwischen Bürgertum und Krone erkannt. So gewann er in diesen Jahren zunehmend das Vertrauen liberaler und insbesondere patriotischer Kreise, die von ihm eine Stärkung der Position Preußens im Deutschen Bund erwarteten.

Die kurz nach dem Antritt seiner Regentschaft am 6.12.1858 erzwungene Demission des reaktionären Kabinetts von Manteuffel war ein Signal für den neuen Kurs. In den bald darauf stattfindenden Wahlen für das Abgeordnetenhaus (Zweite Kammer) erhielten die Liberalen unter Vincke die absolute Mehrheit. In diesem Ergebnis kommt auch der zunehmende Einfluß des zu Wohlstand gekommenen Bürgertums zum Ausdruck, denn das preußische Dreiklassenwahlsystem vom 30.5.1849 gab der kleinen Schicht von >Höchstbesteuerten< allein ein Drittel aller Stimmen; die >Mittelbesteuerten $<$ hatten ein weiteres Drittel, und die Masse des Volkes, die kaum direkte Steuern zahlte, hatte ebenfalls nur ein Drittel der Stimmen.

Eine gewisse Milderung des politischen Drucks war schon 1856 eingetreten, nachdem der verhaßte Polizeichef von Berlin, 
Hinckeldey, am 10.3.1856 das Opfer eines Pistolenduells gcworden war. In diesem Jahr konnte z. B. auch der 1849 seines Amtes enthobene Rudolf Virchow wieder nach Berlin zurückkehren. Am 13.1.1861 erging schließlich eine Amnestie für alle politischen Vergehen, und viele der $1848 / 49$ geflohenen Liberalen und Demokraten konnten zurückkehren und belebten die politische Szene.

Politisches im Verlagsprogramm

chon im Sommer 1858 hatte die von Springer anonym verD legte Schrift Die Politik der Zukunft vom preußischen Standpunkte Aufsehen erregt und mußte sogleich nachgedruckt werden. Ihr Verfasser, Julius Bluhm (1822-1900), war militärischer Berater der osmanischen Regierung und sah dic politischen Perspektiven offenbar wesentlich deutlicher als die in der Tagespolitik befangenen Berliner.
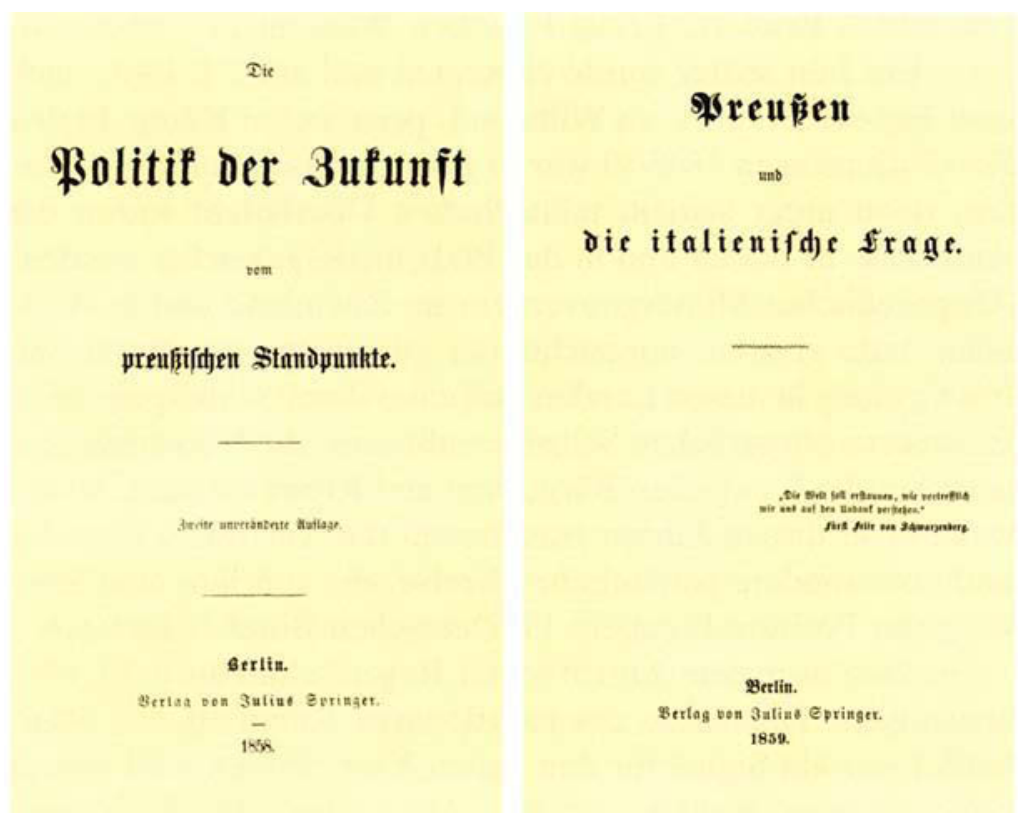

40, 41: Politische Tagesschriften erschienen auch unter dem, Neuen Kurs häufig noch anonym. Die Beitrüge von Julius Bluhm (links) und Constantin Rößler (rechts) mußten schon im Monat des Erscheinens nachgedruckt werden.
In vergleichbarer Weise wirkte Constantin Rößlers (1828 bis 1896) >Sendschreiben an den Politiker der Zukunft<, das sich weitgehend mit dem Programm Bismarcks deckte, der zu dieser Zeit noch preußischer Gesandter beim Frankfurter Bundestag war. Als in diesen Monaten die preußische Regierung nahe daran war, Österreich im Krieg gegen Italien zu unterstützen was Preußen auch in einen Krieg mit Frankreich verwickelt hätte - verlegte Springer von Rößler auch die Schrift >Preußen und die italienische Frage`, die 1859 kurz hintereinander vier 
Auflagen erlebte und ihre Wirkung auch auf amtliche Kreise nicht verfehlt haben dürfte. In Berlin hieß es gar, Bismarck selbst sei der Autor, was wohl sein mochte, denn Rößler hattc diese wie auch seine anderen Schriften zur Tagespolitik anonym veröffentlicht. Bismarck verneinte zwar, soll aber gesagt haben, daß die Darlegungen ganz seinen Auffassungen entsprächen [ADB]. Für mehr als zwei Jahrzehnte war Rößler ein entschiedener Vertreter bismarckscher Ideen und stand zeitweilig auch in dessen Sold.

In diesem Jahrzehnt von 1858 bis 1867 erschienen, historische Bücher mit Zeitbezug eingeschlossen, insgesamt 91 politische Bücher bei Springer, womit dieser Verlagszweig der umfangreichste Sektor der Verlagsproduktion war. Daß Springer besonders für die Fortschrittspartei zu wirken trachtete, ist unverkennbar, doch verlegerisch handelte er getreu seiner schon früher gegenüber Gotthelf geäußerten Überzeugung, »es wäre närrisch von mir, nur Bücher von Autoren verlegen zu wollen, welche meine politischen Ansichten teilten « (24.8.1852). Dies zeigt sowohl sein Verhältnis zu Rößler, der ihm »ein angenehmer Hausfreund wurde « [MS: 56], auch wenn er, im Gegensatz zu diesem, die Politik Bismarcks verurteilte, als auch seine Sympathie für Johann Jacoby oder Heinrich Simon, um nur diese gegensätzlichen politischen Naturen anzuführen. Allerdings wäre kaum ein konservativer Politiker auf die Idee gekommen, politische Manuskripte gerade Springer anzubieten, an dessen Einstellung kein Zweifel bestehen konnte.

Wie bereitwillig sich Springer allen fortschrittlichen Gruppierungen zur Verfügung stellte, zeigt z.B. sein Eintreten für Heinrich Simon, der in der Paulskirche auf Seiten der Linken gesessen hatte und nach der Vertreibung des Stuttgarter Rumpfparlaments wegen Hochverrats zum Tode verurteilt worden war. Er mußte in die Schweiz emigrieren und wurde dort als Unternehmer tätig. Am 16.8.1860 crtrank er beim Baden im Walensee. Freunde des Politikers hatten bald darauf in der Berliner NNational-Zeitung zur Errichtung eines Denkmals für Simon aufgerufen. Springer hatte den Appell mitunterzeichnet und als Flugschrift verbreitet. Als ihm nun 1863 aus der Familie Simons der Antrag gemacht wurde, ein von Johann Jacoby geschriebenes Buch über Simon zu veröffentlichen, sagte er sogleich zu.

Jacoby, Springer aus den Berliner Revolutionstagen noch gut bekannt, trat zunächst nicht in Erscheinung. Er stand unter Polizeiaufsicht und mußte Vorsicht walten lassen. Erstmals war er durch seine , Vier Fragen, beantwortet von einem Ostpreu-
42: Heinrich Simon (1805-1860) gehörte zu den Linksradikalen, die nach der gescheiterten Revolution emigrieren mußten.

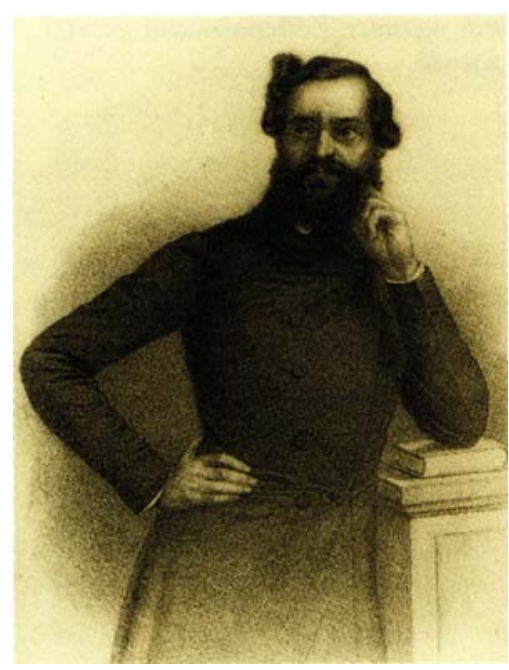




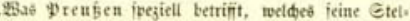
lath ju Deutidlant io gänlid verleren bat, io it ibm

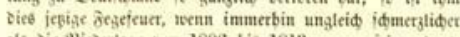
ale bie Mitèerlage ven 1806 bis 1813, - ju feiner beut. i iden Gntwifelung vielleidt netbwentia. 3d geftebe offen,

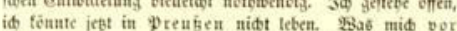
lois emporte, uto mit interlider \%otbwendigfeit ourd meine Beamtenitellumg in bie entidiedenfte Orvefiticn trieb, bie Eisge in iffenttiden Berbailtnifien - fie war jung fraulide Meinbeit gegen bie Quine, bie beute alle Gtaate.

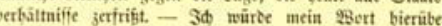
aud jegt nidt juriaffyalten, wernt 98 erte beute nidgt is

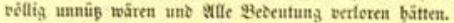
3d eridrede oft im Sinnerfen, ment id bieic noten antifiden 3 uftänte mit ten bieit allen Mrangeln im Ginzelnen fint ber Gbrti申teit une

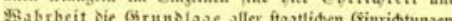

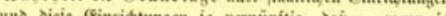
Wos chliuf Der 9?

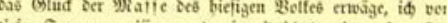
fiefer Srauter ergrifien werice, fo eft i申 samit uniere 3 u frinte vergleide. Thu materiellem tsebliein bat fid bier eine Gelbftänbigfeit bes (Sbarafters entwidelt, bie Den Mienidenfreun mit ôteube erüult.

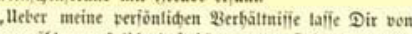

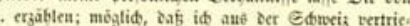
ten merte; if merce bat in Mube binnebmen, wic mein Banted Gdifial, - als cine Senieaucus meiner Sufidten

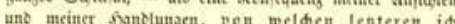

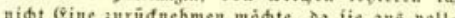

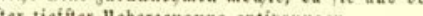
Ireulid Dein Areumb

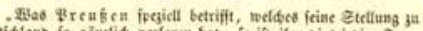

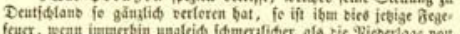

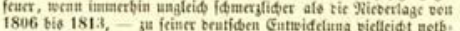

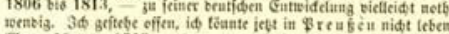

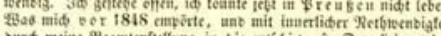

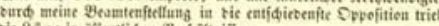

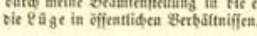

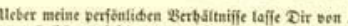

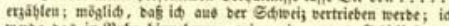
wertse bad in STube biancebmen, wie meit ganjes Edidfial.

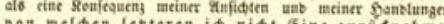

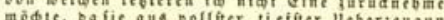

43, 44: Abgebildet ist oben der Text der ersten Ausgabe (Bd.2, S. 142f.), unten der der, Volksausgabe. (S. 312). Die in dem hier zitierten Brief von Simon beanstandeten Stellen sind durch einen abweichenden Farbton kenntlich gemacht. Es ist zu erkennen, daß der spätere Druck aus einer kleineren Schrift mit weniger Zeilenabstand gesetzt wurde.
Ben< (1841) in weiteren Kreisen bekannt geworden. Im Mai 1848 war er bei einer Nachwahl zum Berliner Stadtrat erfolgreich gegen Rudolf Gneist angetreten und hatte im November 1848 dem König die berühmt gewordenen Worte nachgerufen: $\gg$ Das ist das Unglück der Könige, daß sie die Wahrheit nicht hören wollen.« Als in Königsberg ein Hochverratsprozeß gegen ihn angestrengt wurde, war er aus dem sicheren Schwcizer Exil in seine Heimatstadt zurückgekehrt und hatte den Prozeß zu seinen Gunsten entscheiden können.

Das Buch >Heinrich Simon. Ein Gedenkbuch für das deutsche Volk $<$, herausgegeben von Johann Jacoby, crschien im Sommer 1865. Die Presse brachte sofort ausführliche Rezensionen, und manche Blätter hatten den Inhalt spaltenlang in mchreren Folgen referiert. Als ein Verbot des Buches erging, war die Auflage schon nahezu vergriffen. Springer befand sich gerade mit sciner Familie zur Erholung in Bad Elster, als eine Depesche ihn von dem Vorgang unterrichtete. Fieberhaft suchte man nach den sechs Stellen, dic höheren Orts Anstoß erregt hatten. Springer beschloß, sogleich eine cinbändige Ausgabe drucken zu lassen. Die von ihm nach Rücksprache mit dem Autor vorgenommenen Streichungen teilte cr der Staatsanwaltschaft mit und crhielt am 21.11.1865 die Zusage, daß der Veröffentlichung nichts mehr im Wege stehe. In der Neuausgabe ließ Springer die inkriminicrten Stellen durch Gedankenstriche ersetzen. Wer nur die gereinigte Ausgabe bekommen hatte, brauchte sich um eine Abschrift der gestrichenen Partien nicht lange zu bemühen.

Politik, Recht, Wirtschaft, Philosophie und Theologie werden von Bibliographen aus gutem Grund getrennt rubriziert, und so geschieht es auch im Gesamtkatalog des Verlags. Julius Springer hätte dies für sein Programm wahrscheinlich mißbilligt, denn fast alle diese Bücher und Broschüren waren für ihn und seine Zeit thematisch kaum zu trennen. Sie behandelten Zustände der Gesellschaft und betrafen das Gemeinwohl insgesamt.

Fragen der Verfassung, des Strafprozesses, der Unabhängigkeit unterer Instanzen der Gerichtsbarkeit oder der Geschworenengerichte waren in dieser Zeit hochpolitische Themen. Dies galt auch für Schriften über Freihandel und Schutzzölle, über Steuern, Gewerbe- und Aktienrecht. Und wenn Springer die Bücher des Rabbiners Samuel Holdheim, der der > Jüdischen Reformgemeinde $<$ Berlins seit 1847 vorstand, oder Schriften des Reformtheologen und Begründers der Wissenschaft vom Judentum Leopold Zunz veröffentlichte, so geschah dies aus der gleichen Gesinnung, die ihn bewog, Flugschriften zum DeutschKatholizismus, solche über die Redefreiheit der Geistlichen in 
der evangelischen Kirche oder die Konfessionsschule zu verlegen. Alle diese Schriften sind Zeugnisse wider die Einengung bürgerlicher Freiheiten, die einseitige Benachteiligung einzelner Bevölkerungsgruppen und gegen die Gängelung der Bürger durch den Staat oder die Kirchen.

Neben diesen Veröffentlichungen zumeist geringeren Umfangs stehen große verlegerische Unternehmen wie das dreiteilige Werk Rudolf Gneists über >Das heutige englische Verwaltungsrecht mit Einschluß des Heeres, der Gerichte und Kirche< mit 1375 Seiten (1866/67), Paul Limans $>$ Der preußische Straf-Prozeß<, 1859 mit 600 Seiten vorgelegt, oder $>$ Dic Staatseinrichtungen Englands $<$ von Homersham Cox $(1867,677$ Sciten). Es ist unmöglich, hier auf die zahllosen Einzelveröffentlichungen theologischen, juristischen, staatsrechtlichen oder wirtschaftlichen Inhalts im Detail einzugehen oder gar ihre tagespolitischen Bezüge darzustellen.

$\mathbf{J}^{\mathrm{u}}$ ulius Springer bekannte sich zur Fortschrittspartei [MS: 67], die sich 1861 von den Altliberalen Vinckes getrennt und mit den linksliberalen Abgeordneten vereinigt hatte. Bcide Grup-

Der Verlag im

Verfassungskonflikt pierungen stimmten überein in der entschiedenen Gegnerschaft

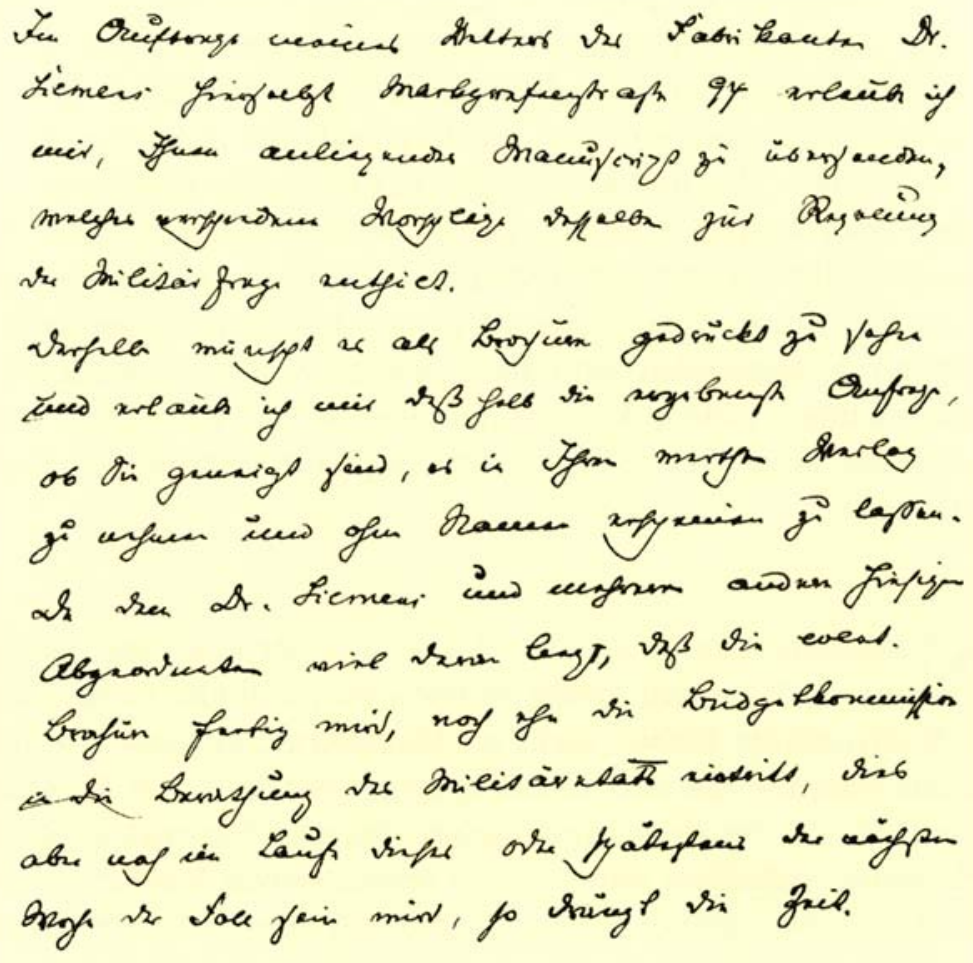

45: Werner Siemens gab seine Flugschrift Zur Militärfrage durch seinen Vetter Georg, später Grïnder der Deutschen Bank, Springer zum Verlag. Georg Siemens schrieb am 30.6. 1862: Im Auftrage meines Vetters des Fabrikanten Dr. Siemens hierselbst Markgrafenstraße 94 erlaube ich mir, Ihnen anliegendes Manuscript zu übersenden, welches verschiedene Vorschläge desselben zur Regelung der Militärfrage enthielt |!/. Derselbe wünscht es als Brochure gedruckt zu sehen und erlaube ich mir deßhalb die ergebenste Anfrage, ob Sie geneigt sind, es in Ihren werthen Verlag zu nehmen und ohne Namen erscheinen $z u$ lassen.« 
zur geplanten Heeresform und der Ablehnung der Außenpolitik Bismarcks. Der Feldzug gegen Dänemark wurde zur Belastungsprobe für die Partei, der siegreich beendete deutschösterreichische Krieg führte dann zur Sezession der bismarckfreundlichen Nationalliberalen.

Aus der Verlagsperspektive gesehen stand am Anfang der Diskussionen die bei Springer anonym veröffentlichte Schrift ,Zur Militärfrage<, in der Werner Siemens namens einiger Fraktionsfreunde die Frage aufwarf, »ob sich nicht auf einem anderen als dem von der Regierung vorgeschlagenen Wege die [angestrebte] Verdoppelung der Armee für den Kriegsfall erreichen ließe«. Man kam aber zu keiner Verständigung. Am Ende des innerparteilichen Streits stand die Spaltung, deren Zwangsläufigkeit von Springers früherem Parteifreund, dem Literarhistoriker Julian Schmidt, in seiner Schrift >Die Notwendigkeit einer neuen Parteibildung< begründet wurde. Sie war am 29.7.1866 abgeschlossen und mußte noch im selben Jahr viermal nachgedruckt werden. Die rechten Liberalen waren für die nachträgliche Anerkennung der unter Ausschaltung der Zweiten Kammer beanspruchten zusätzlichen Militärkredite (>Indemnitätserklärung ), die Fortschrittspartei war nicht zu einem Kompromiß bereit.

Springer, der beide Schriften und noch manche weitere zum Verfassungskonflikt publiziert hatte, stand weiterhin zu der nun in die Minderheit geratenen Fortschrittspartei, der u. a. auch der Pathologe Rudolf Virchow angehörte. Als in der Folgezeit dic linken Liberalen in den Vordergrund traten, zog Springer sich aus den Diskussionen seiner Partei immer mehr zurück, blieb aber weiterhin in den Bezirksversammlungen aktiv. So wurde er 1868 erneut in den Stadtrat gewählt und in seinem Amt auch drei Jahre später bestätigt. Daß er 1876 zum Vertreter des >linken< Vorsitzenden Straßmann gewählt wurde, verdankte er offensichtlich einem Kompromiß und seiner Fähigkeit, zwischen den zerstrittenen Fraktionen ausgleichend zu wirken [vgl. MS: $165 \mathrm{f}$.$] .$

Reisebücher und $\mathbf{N}$ achdem bekannt geworden war, daß Springer sich künftig Belletristisches 1 nur noch seinem Verlag widmen werde, fehlte es auch auf belletristischem Gebiet nicht an Manuskriptangeboten. Einer dieser Autoren, die sich nun an Springer wandten, war Theodor Fontane, der bis dahin noch keine angemessene verlegerische Heimstatt gefunden hatte. Scine crsten sieben Bücher waren immerhin bei fünf Verlegern erschienen. Am 30.1.1860 fragte er bei Springer an, ob dieser geneigt sei, »den Verlag eines 
Skizzen- und Reisebuchs zu übernehmen«, das er unter dem Titel $>$ Jenseit des Tweed $<$ herausgeben wolle. Da die Mehrzahl der Beiträge bereits im Feuilleton verbreiteter Zeitungen abgedruckt worden war, wolle er sich mit einem Honorar von 150

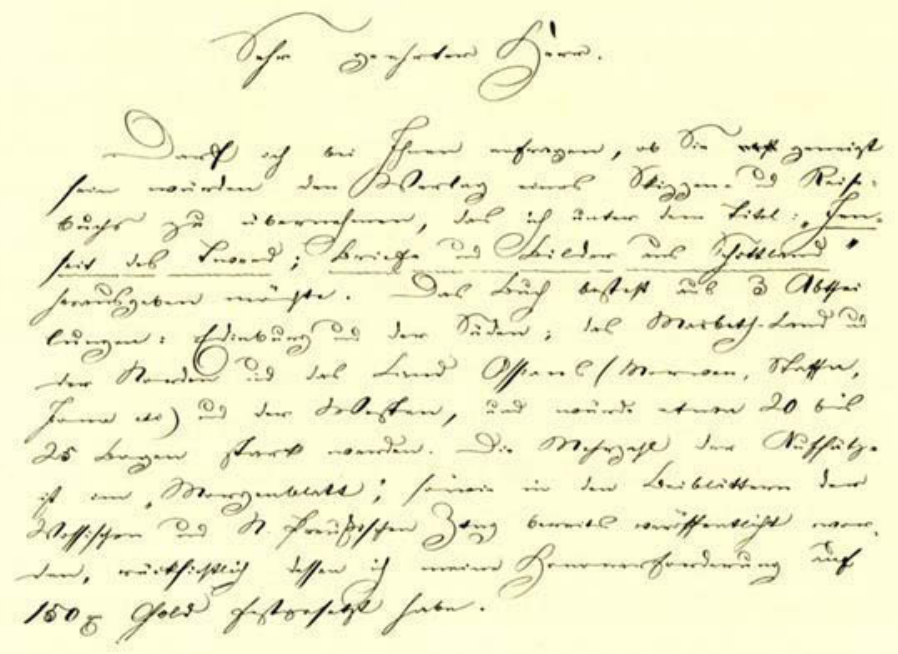

Talern begnügen. Springer sagte zwar zu, war aber nur zu einem Honorar von hundert Talern bereit, was der Dichter, in akuter Geldnot, schließlich akzeptierte. Der Satz dauerte acht Wochen, und im August 1860 erschien dann das Buch. Nach anfangs recht gutem Absatz blieb es aber bald stecken. Im Januar 1890 überlic $\beta$ Ferdinand Springer das $>$ Verlagsrecht (nebst Vorräten) < dem Verlag Fontane \& Co.

Zunächst hatte sich Fontane wegen seines Buchprojekts an Paul Heyse mit der Bitte gewandt, seine >Schottische Reise< dem Verleger Wilhelm Hertz zu empfehlen. Dieser war einer der renommicrtesten Verleger seiner Zeit und betrcute unter anderem auch sehr erfolgreich das Werk von Heyse. Doch inzwischen zögerte Fontane, Hertz eine Sammlung früher erschienener Arbeiten anzubieten. Zwei Absagen hatte er von Hertz schon bei anderer Gelegenheit bekommen. Dic dritte wäre nun zu erwarten gewesen, zumal Fontane bei Ebner \& Seubert in Stuttgart gerade ein einschlägiges Buch ( $>$ Aus England $<$ ) unter Vertrag hatte. Hertz fehlte zudem das rechte Vertrauen zu Fontanes Marktgängigkeit, da es diesem, wie er Heyse anvertraute, »trotz wirklich feiner Arbeiten, nicht recht geglückt ist, sich einen Kreis [interessierter Leser] zu schaffen « [DAvidIS (1): 1384]. Hertz gab Fontane schließlich die Empfehlung, sein Buch Springer anzubieten. Da Hertz und Springer einen freundschaftlichen Kontakt hatten, ist zu vermuten, daß sie sich vorher
46: Das Verlagsangebot Fontanes vom 30.1.1860 lautet: "Sehr geehrter Herr. Darf ich bei Ihnen anfragen, ob Sie geneigt sein wïrden den Verlag eines Skizzen- und Reisebuchs zu übernehen, das ich unter dem Titel $>$ Jenseit des Tweed; Briefe und Bilder aus Schottland herausgeben möchte. Das Buch besteht aus 3 Abtheilungen: Edinburg und der Süden; das Macbeth-Land und der Norden und das Land Ossians (Morven, Staffa, Iona etc) und der Westen, und würde etwa 20 bis 25 Bogen stark werden. Die Mehrzahl der Aufsätze ist im >Morgenblatt<, sowie in den Beiblättern der Vossischen und N. Preußischen Ztng bereits veröfentlicht worden, rücksichtlich dessen ich meine Honorarforderung auf 150 Rthl. Gold festgesetz, habe. - Theodor Fontane gab Springer nur dieses eine Buch zum Verlag. Die weiteren erschienen dann bei Springers Freund Wilhelm Hertz.
47: Aufnahme von Theodor Fontane; um 1865.

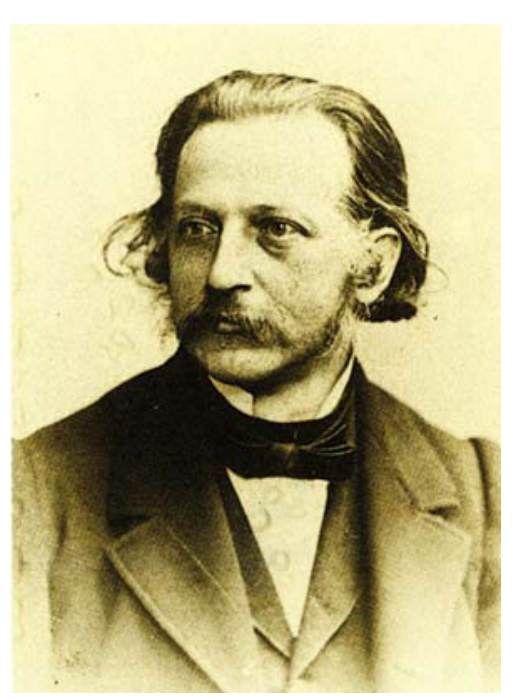


48 (gegenüberliegende Seite): $Z_{u}$ Weihnachten 1862 bot Springer immerhin 7 neue Kinderbücher an. Mit $331 / 3 \%$ Rabatt und Partie $7 / 6$ lieferte er gegen feste Rechnung, schloß jedoch den Barbezug über seinen Kommissionär aus. abgestimmt hatten. Angemerkt sei schon bei dieser Gelegenheit, daß Springers ältester Sohn Ferdinand 1864 seine Lehre bei Hertz antrat und später dessen Testamentsvollstrecker wurde. Und 1879 hciratete Springers zweitältester Sohn Fritz Emma Hertz, die zweite Tochter seines Freundes.

Ende 1860 sondierte Fontane schließlich bei Hertz wegen seiner $>$ Wanderungen durch die Mark Brandenburg $<$ : »Meinen Sie, daß ich Springer frage, ob er es nehmen will? Der Inhalt ist entschicden konservativ (nicht in dem häßlichen Sinne von >reaktionär $\varsigma$ ) woran S. allerdings wohl Anstand nehmen dürfte « [FonTANE: 21]. Fontane sprach von Springer und meinte natürlich Hertz, der sehr entschieden konservativ im Sinne Fontanes war und der sich trotzdem mit dem liberalen Springer trefflich verstand. Im nächsten Jahr verlegte Hertz Fontanes > Balladen<, und seit 1862 erschienen bei ihm die $>$ Wanderungen $<$. Bis auf einige Ausnahmen hat Hertz dann das Werk von Fontane betreut, und beide waren recht zufrieden miteinander.

Zur Reiseliteratur gehören auch die Bücher von Julius Rodenberg, von 1874 bis 1914 Herausgeber der >Deutschen Rundschau< und viclseitiger Schriftsteller. Bei Springer erschienen scine Skizzen >Alltagsleben in London<. Da sic im selben Jahr wic Fontanes Schottlandbuch herauskamen, könnten sich beide Bücher am Markt etwas im Wege gewesen sein. > Verschollene Inseln< und die Tagebuchblätter >Stilleben auf Sylt< folgten cin Jahr später. Letzteres Werk crlcbtc 1876 noch eine dritte Auflage und ist seit 1979 sogar als Reprint verfügbar.

Gleichfalls 1860 erscheinen von Saltykow(-Schtschedrin) sSkizzen aus dem russischen Landleben<, übersetzt von dem Balten A. Mecklenburg, eine deutsche Erstausgabe des russischen Satirikers, die noch heute geschätzt wird. Ansonsten verdienen die Bücher aus Springers belletristischem Angebot kcine besondere Aufmerksamkeit. Es zeigt sich vielmehr, wie treffend Marie Springers Urteil aus dem Jahre 1877 war: ihr Mann »eignete sich indessen entschieden nicht für dies Genre « [MS: 56]. Auch unter den Produktionen seiner Söhne und Enkel finden wir lediglich Vereinzeltes, verlegt wohl nur aus Sympathie für einen befreundeten Autor. Es sind alles Namen, die keine neuere Literaturgeschichte mehr nennt. ${ }^{12}$

Ausbau und Ende des Jugendbuchverlags

\footnotetext{
$\mathrm{D}$
} er mit den Büchern Hermann Kletkes begonnene Jugendschriftenverlag hatte sich gut eingeführt, und Springer baute ihn in den 60er Jahren weiter aus. Zu den Jugendsachbüchern Kletkes kamen nun auch > Erzählungen für die reifere weibliche Jugend<, Märchen, Theaterstücke und Rätselbücher 


\title{
Jugendschriften. Weihnachten 1862.
}

\author{
moxisestam
}

Ende September kommen nachstehende

\author{
Neue Jugendschriften
}

zur Versendung:

Coopers Lederstrumpf-Erzählungen. Für die Jugend bearbeitet von Adam Stein. 25 Bogen. Mit sechs Zeichnungen von G. Bartsch. In festem Einbande. Preis 1 Thlr. Cooper's Lederstrumpf-Erzählungen sind eines der beliebtesten und leicht verkäuflichsten Jugendbücher. Die neue von Adam Stein mit grossem Geschick geschehene Bearbeitung, mit ganz vorzüglich gelungenen Zeichnungen von $G$. Bartsch geschmückt, in einem mit Cattunrücken versehenem festem Einbande, darf bei dem überaus wohlfeilen Preise von 1 Thaler ord. auf ein grosses Publikum rechnen: die Ausgabe wird eines der leicht verkäuflichsten Jugendbücher werden.

Memoiren eines sechszehnjährigen Mädchens. Von Elise Halm. 15 Bogen. Mit einem Titelbilde. In cartonirtem Einbande.

Preis 1 Thlr.

Resi. Eine Erzählung für die reifere weibliche Jugend. Von Aurelie. 10 Bogen. Mit einem sauberen Titelbilde. In cartonirtem Einbande.

Preis $22 \%$ Sgr.

Erzählungen für junge Mädchen. Von Marie Elisabeth. 16 Bogen. Mit drei Zeichnungen von G. Bartsch. In cartonirtem Einbande.

Preis 1 Thlr.

Die Zahl der für Mädchen im Alter von 12-16 Jahren empfehlenswerthen Bücher ist sehr klein; die vorliegenden drei Jugend bü cher sollen diese Lücke in unserer Jugendschrift-Literatur ausfüllen; sie werden von jungen heranwachsenden Maidehen mit lebhaftem Interesse und zur Förderung ihrer Bildung gelesen werden.

Der runde Tisch. Geschichten für Kinder von 6-9 Jahren. Von R. Hortex. 13 Bogen. Mit secks coloriten Zeiclmungen. In verziertem Farbendruck-Umsehlag cartonirt.

Preis 27 Sgr.

40 kleine Geschichten für das zarte Alter, fesselnd und anmuthig erzählt; ein sehr hûbsches Buch.

Erzählungen für Kinder von 2-7 Jahren. Von Ida seele. 10 Bogen. Mit sechs colorirten Zeichnungen. In verziertem Farbendruck-Umschlag cartonirt.

Preis 24 Sgr.

87 Erzähiungen, eingetheilt in Plaudereien - Märchen - Erzählungen ernsten und heiteren Inhalts - Natnrgeschichtliche Erzählungen - Moralische Erzählungen - Erzählungen aus der Bibel, dem bezeichneten Alter von 2-7 Jahren anpassend, mit grossem Takte in Wahl und Behandlung des Stoffes und der Sprache zusammengestellt - ist das ein Buch, das überall gefallen wird.

Nouveau Recueil de Comédies, Proverbes et Charades dramatiques a l'usage des maisons d'éducation et des familles par Catherine Narbel. 19 Bogen. Mit einem Titelbilde. In cartonirtem Umschlage.

Preis 1 Thlr.

Diese neue Sammlung französiseher Komödien ete, schliesst sich der im vorigen Jahre erschienenen Sammbung an; für die gute Auswahl bürgt der Name der Herausgeberin.

Ich gebe diese neuen Jugendschriften, wie meinen übrigen JugendschriftenVerlag mit $33 \frac{1}{3} \%$

und fortan (jeden Baarpreis ausschliessend)

auf Rechung, fest - auf einmal bezogen - auf je $\boldsymbol{I}$ Exemplare 1 frei also über $40 \%$. 
weiterer Autoren. Von 1858 bis 1865 veröffentlichte der Verlag immerhin 42 Titel. Bei durchschnittlich fünf Jugend- und Kinderbüchern pro Jahr, die regelmäßig im Herbst und damit rechtzeitig zum Weihnachtsgeschäft erschienen, konnte man schon von einer Spezialisierung sprechen.

Fruchtbarste Autorin von Mädchenbüchern war Sophie Gräfin von Baudissin, eine Tochter des Berliner Bankiers Kaskel, die unter dem Pseudonym >Aurelie < oder > Tante Aurelie < schon bei Hallberger in Stuttgart und bei Janke in Berlin einige Bücher veröffentlicht hatte. Bei dieser Autorin erfuhr Springer, wie zeitaufwendig die Korrespondenz mit einer Dame höherer Kreise sein konnte. Wohl jede Woche kam ein längerer Brief der Autorin und wollte beantwortet sein. Bei seinem Erfolgsautor Kletke hatten für ein Buch jeweils ein paar kurze Mitteilungen hin und her genügt.

1861 entzweite sich Springer mit seinem Erfolgsautor wegen einer Lappalie, und Kletke wandte sich anderen Verlagen zu. Doch noch im selben Jahr ergab sich zum Glück Springers der Kontakt zu einem Autor, der die entstandene Lücke zu füllen geeignet schien. Robert Springer, im Alter des Verlegers, mit diesem aber nicht verwandt, hatte an einer höheren Mädchenschule unterrichtet, ehe er sich dem Journalismus zuwandte. Unter dem Pseudonym Adam Stein bzw. Robert Wagner gab er 1861 bis 1865 ncun Jugendbücher für Springer heraus, und zwar ausnahmslos Übersetzungen bzw. Bearbeitungen von Erzählungen Coopers (u. a. >Lederstrumpf $<$ ), Scotts (>Ivanhoe<, >Kloster und $A b t<$, Quentin Durward $<$ ), Reids und Aimards. Dic Lederstrumpf-Erzählungen waren trotz einer Auflage von immerhin 3000 Exemplaren schnell vergriffen und wurden gleich nachgedruckt. Dies hatte Springer auch zu entsprechend hohen Auflagen bei den folgenden Büchern ermutigt, doch der Erfolg blieb dann aus; offenbar hat keines der späteren Bücher von Robert Springer auch nur die Aufwendungen gedeckt.

Bei der Kritik fand das Engagement des Verlegers durchaus Anerkennung, wie eine zeitgenössische Rezension zeigt:

Die Jugendschriften, welche im Verlage von Julius Springer hierselbst seit einer Reihe von Jahren erschienen sind, zeichnen sich stets durch Einfachheit und Wahrheit in der Darstellung und durch die Herzlichkeit der in ihnen geschilderten Gesinnungen aus. Es ist keine geringe Kunst, für die Jugend zu schreiben. Die Bilder, welche die Jugendschrift vorführt, müssen das wirkliche Leben treffen, doch sollen sie weder dem Verstande noch der Phantasie die vollständige Reife zumuten; zugleich müssen sie sich von der Altklugheit fernhalten. Die Jugendschrift soll Menschen von Fleisch und Blut, keine Flitterpuppen und sententiöse Gestalten zeigen, und doch soll sie die realen Leidenschaften höchstens leise andeuten. Das ist eine Aufgabe, welche einen 
zarten Takt verlangt. So viel wie wir von den Verlagsartikeln des Herrn Julius Springer gesehen, ist in denselben jene Aufgabe erfüllt (PreuBisches Volksblatt, 9.12.1862).

Das Kinder- und Jugendbuchgeschäft war schwieriger geworden: Die Preise mußten niedrig gehalten werden, es wurde ein fester Einband erwartet, der vor der Industrialisierung der Buchbindereien noch recht teuer war, eine gute Illustrierung war notwendig, für die Springer u. a. Theodor Hosemann, Gustav Bartsch, Ludwig Burger, August Haun und Ludwig Pietsch verpflichtete. ${ }^{13}$ Und die zunehmende Konkurrenz trieb auch die Rabatte hoch: seit 1860 lieferte Springer die sgemischte Partie $7 / 6$, gegen Rechnung mit 33 $\frac{1}{3} \%$ Rabatt. Da von sieben gelieferten Büchern nur sechs berechnet wurden, ergab dies also cinen Rabatt von etwa $43 \%$. Unter solchen Bedingungen war der Verkauf einer Auflage von 3000 bis 4000 Excmplaren erforderlich. Dieses Geschäft konnte nur noch profitabel betrieben werden, wenn er ihm scine ganze Kraft widmete. Hierzu war Springer aber offenkundig nicht bereit.

Mit Rundschreiben vom 10.2.1866 teilte er dem Sortimentsbuchhandel mit, »daß er seinen Jugendschriften-Verlag (inclusive Auslieferungen 1866 und Ostermesse 1866 disponierte Artikel) an Herrn Alfred Oehmigke in Neu-Ruppin mit allen Verlagsrechten käuflich überlassen « habe. Es werden zwar Gründe bei solchen Verkäufen üblicherweise nicht angegeben, doch man kann sie aus der Schlußbemerkung Springers unschwer erraten, in der cr bittet, seinem Verlage sowie seinen neuen Unternehmungen das lebhafte Interesse zu bewahren. Und für dic neuen Projekte brauchte er flüssiges Kapital.

Der Ablauf der Transaktion des Verkaufs mag für Fachgenossen auch heute noch von Interesse sein: Am 29.9.1865 hatte Springer im Börsenblatt durch Julius Krauß einen Käufer für seinen Jugendbuchverlag gesucht und als Preisvorstellung 14000 bis 15000 Taler genannt. Krauß, seit 1855 der erste festangestellte Redakteur des Blattes (für 600 Taler Jahresgehalt), hatte sich diskret der Hin- und Herleitung von Anfragen angenommen. Schon im Oktober 1865 kam ein Kontakt zwischen Springer und Oehmigke zustande, und zwei Monate später war man sich über die Größenordnung der Kaufsumme für die 55 Titel einig. Sic betrug schließlich 8825 Taler und war zahlbar in drei Raten. Ein ab Januar 1867 noch offener Rest sollte mit $4 \frac{1}{2} \%$ verzinst werden. Springer hatte also deutlich unter seinen Erwartungen abschließen müssen.

Julius Krauß, der Vermittler, war mit einer Entschädigung von 35 Talern recht zufrieden, denn er hatte nur vier kurze
49: Außer durch ein Circular gab Springer den Verkauf seines Jugendschriften-Verlags am 10.2.1866 auch durch eine Anzeige im Börsenblatt bekannt. Teil der Bekanntmachung (hier nicht abgebildet) war eine Information von Oehmigke.

[5017.] Nachstehendes Circular wurde an die g. Sortimentshandlungen versandt: Berlin, den 10. Februar 1866. Icb beehre mich Ibnen hiermit aazazeigen, dass ich meinea Jugendschriften-Verlag

(inclusive der Auslieferungen 1866 und der Ostermesse 1866 dispouirten Artikel)

an Herrn Alfred Oehmigke in Neu-Ruppin

mit allen Verlagsrechten käuflicb überlassen habe.

Ueber die von meinem Conto auf das des Herrn Alfred Oebmigko zu übertragenden Sendungen 1S66, wie Disponenden, werden Ihnen später specificirto Angabon zugehen.

Dem geehrten Sortimentshandel sage ich meinen Dank für die besondere Gunst, welche derselbe meinem JugendschriftenVerlage hat zu Theil werden lassen, and Besitzer zu schenken, und meinem andern Besitzer zu schienken, und meinem ander Verlage, wie meinen neuen Unternehman. Achtungsvoll Jalius Springer. 
Briefe zu schreiben gehabt. Scinc Geschäftsbedingungen sahen sonst, bei intensiveren Bemühungen, eine Provision von $1 \% \mathrm{der}$ Kaufsumme vor.

Schulbücher ein erstes Schulbuch hatte Springer 1847 mehr aus Gefälligkeit verlegt: cine Griechische Formenlehre für die unteren und mittleren Gymnasial-Classen< von Carl Franke, Lehrer am Joachimsthalschen Gymnasium. Dic bis dahin an den Berliner Gymnasien eingeführte Grammatik von Buttmann war zu weitschweifig und für Anfänger auch zu unübersichtlich. Hinzu kam noch, daß die einzelnen Auflagen so sehr voneinander abwichen, daß in manchen Klassen bis zu acht verschiedene Versionen in Gebrauch waren. Ohne besondere Werbung und ohne parallele Titel konnte Springer seine Ausgabe mit gutem Erfolg absetzen.

Später kam einzelnes hinzu: ein Lehrbuch der französischen Sprache (1848), das mit seinen 48 Seiten aber kaum viel geboten haben kann, eine > Taschen-Grammatik der französischen Sprache ( 1851 ) und eine > Arithmetik und Algebra für Gymnasien

50: Carl Frankes Griechische formenlehre war Springers erster und recht erfolgreicher Schritt auf den Schulbuchmarkt. Adolf Kirchhoff, der Bearbeiter der 2. Auflage, wurde später als klassischer Philologe bekannt. Ab der 7. Auflage (1872) betreate der Schulmann Albert von Bamberg die Grammatik.

(5) riedifoce

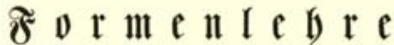

fât

Dic unteren uno mittleren Gymmafiat-Glaffich

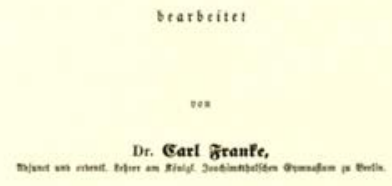

Berlin, 1847. 9uthas ven 3utiut avringet und Realschulen< (1857). Dazuzuzählen wäre vielleicht Dannebergs > Theoretisch-praktischer Leitfaden der deutschen Stenographie oder Kurzschrift nach dem Stolze'schen System`, der 1851 erschicn.

Diese Veröffentlichungen lassen noch kcinen Plan erkennen, einen Schulbuchverlag aufzubauen. Ansätze hierzu gibt es erst nach dem Verkauf des Sortiments 1858. In diesem Jahr erscheinen vier Hefte > Römische Literaturgeschichte und Altertümer, für höhere Lehranstalten bearbeitet<, ein Werk, das günstig aufgenommen wurde und noch manche Neuauflage erlebte, sowie >Winke für Gesanglehrer in Volkschulen<. Dieses Büchlein des mit Springer befreundeten Rudolph Lange erlebte im 19. Jahrhundert immerhin neun Auflagen.

Im Mittelpunkt der verlegerischen Interessen Springers standen Gymnasialbücher, und hier wiederum bevorzugte er Sprachlehrbücher und Lesetexte, Geschichte und Musik. Anfang der 60er Jahre, mit der Aufwertung der Realschulen, kamen auch Mathematik und Chemie hinzu.

1858 konnte Springer Adolf Kirchhoff, einen Schwager Frankes, als Bearbeiter einer Neuausgabe der $>$ Griechischen Formenlehre< gewinnen. Wegen des Neusatzes frage er am 6.12. 1858 bei der angesehenen Druckerei von B. G. Teubner in Leipzig an. Springer hatte im wesentlichen zwei Wünsche: die Lieferung des Buches sollte in acht Wochen erfolgen, und die griechische Schrift sollte deutlicher kommen, »wie Ihre gefei- 
erte Officin dies leicht treffen wird «. Beides konnte Teubner zusagen. Das Buch kam rechtzeitig zum Beginn des Schuljahres und erlebte allein zu Springers Lebzeiten 11 Auflagen.

Mit 77 Schulbüchern - pädagogische Werke eingeschlossen hatte dieser Verlagszweig in der Zeit von 1858 bis 1877 die drittstärkste Position in Springers Verlag. Da die Auflagen über dem Durchschnitt der übrigen Verlagsproduktion lagen und häufiger auch nachgedruckt werden mußten, werden die Schulbücher wirtschaftlich eine wesentliche Stütze des Verlags gewesen sein. Wie plagenreich aber schon damals dic Einführung von Schulbüchern war, soll an einem Beispiel gezeigt werden.

$\mathrm{D}$ ie höhere Schulbildung wurde bis zur Mitte des 19. Jahrhunderts ausschließlich von den Gymnasien vermittelt. Schwerpunkte des Unterrichts bildeten die alten Sprachen soLehrbuchs wie Deutsch und Geschichte. Zunehmend wurde jedoch beklagt, daß die Abiturienten in den modernen Sprachen und den Naturwissenschaften kaum oder nicht hinreichend unterrichtet wurden. Dies war eine Chance für die Realschule, die nicht auf die akademische Laufbahn, sondern auf die bürgerlichen Berufe oder auf Staatsämter vorzubereiten hatte, in denen es mehr auf die > Realien< ankam. Eine preußische Unterrichts- und Prüfungsordnung aus dem Jahr 1859 legte nun die Bedingungen für diesen neuen Schultyp fest und unterschied hierbei Realschulen erster und zweiter Ordnung, später nur noch (Ober-)Realschule und Mittelschule genannt. Die Schulen Erster Ordnung hatten zwar noch Latein als Pflichtfach, sollten sich ansonsten aber stärker dem Unterricht der Naturwissenschaften und der modernen Fremdsprachen zuwenden.

An deutschen Schulen war Französisch als Unterrichtsfach üblich, doch nun kam der Wunsch auch nach einer schulischen Unterrichtung im Englischen auf. Die englische Literatur (Dikkens, Bulwer, Scott, Thackeray, Wilkie Collins u.a.) hatte durch zahlreiche Übersetzungen und seit 1841 auch in den preiswerten Tauchnitz-Ausgaben viele Liebhaber gefunden; englische Techniker, Handelsreisende und Touristen besuchten Deutschland, und deutsche Kaufleute und Ingenieure reisten zur Fortbildung oder gar in der Hoffnung auf eine berufliche Karriere nach England oder Amerika. Aber es gab noch kaum Lehrbücher, die diesem Bedarf gerecht wurden. Verfügbar waren lediglich sprachgeschichtliche und etymologisch orientierte Grammatiken, die für den Schulgebrauch untauglich waren.

Springer, der für englische Lebensformen besonders aufgeschlossen war, selbst aber die Sprache - im Gegensatz zu seiner 
Frau - nicht beherrschte, griff sofort zu, als ihm im November 1864 Rudolf Sonnenburg, Englischlehrer an einer Realschule Erster Ordnung in Danzig, seine neuartige englische Grammatik anbot, die zugleich auch für den Selbstunterricht angelegt war. Nachdem ihm der Autor die Einführung seines Buches in den Schulen von Danzig und Elbing glaubhaft gemacht hatte, sagte Springer verbindlich zu.

Die erste Auflage sollte 3000 Exemplare betragen, als Honorar waren 8 Taler und 15 Groschen je Druckbogen vereinbart, wobei allerdings ein Umfang von mehr als 20 Bogen nicht honoriert werden sollte. Der größere Teil des Manuskripts war schon Ende 1864 eingetroffen, der Rest ging dann Ende Februar auf den Weg; Mitte April 1865 lag das Buch mit einem Umfang von 22 Bogen vor und kostete 24 Groschen. Springer hatte zwar für 25 Groschen plädiert, aber der Schulmann rict ab; das sci zu viel für ein solches Buch.

Zum Schulbeginn kam das Buch natürlich zu spät, denn zuvor mußte es ja bekanntgemacht werden, und hierfür waren auch damals behördliche Empfehlungen eine wesentliche Voraussetzung. Die erste Absage kam schon am 18.4.1865 vom >Königlichen Provinzial Schul-Kollegium< für Berlin und Brandenburg. Man sah sich »nach den von uns befolgten Grundsätzen nicht veranlaßt, ... die von Ihnen nachgesuchte öffentliche Empfehlung... zur Einführung in Schulen eintreten zu lassen «. Es bleibe dem Verlag überlassen, sich selbst an die Lehrer zu wenden. Gebühr der Auskunft: 1/3 Taler. Ähnlich negativ lauteten die Auskünfte der Provinzialregierungen in Breslau, Stettin und Koblenz. In Posen vermerkte man lakonisch, es bestehe hier kcin »Bedürfnis an einer englischen Grammatik «.

Nun mobilisierte Springer seine Kontaktpersonen. Besonders die Verbindung zum Stadtschulrat Eduard Cauer, einem Sohn des Leiters der Cauer'schen Anstalt und mit Springer von Jugend auf gut bekannt, mag gewiß eine Hilfe gewesen sein. Natürlich nannte auch der Autor seinem Verleger Adressen, an die Prüfstuicke zu schicken sich lohnen könnte. Endlich kam im Juni aus Magdeburg die gute Nachricht, daß Sonnenburgs Buch »ausnahmsweise« den Dircktoren der Realschulen »bei eintretender Bedürftigkeit zur Einführung empfohlen« worden sei. Springer merkte aber bald, daß Empfehlungen dieser Art noch keinen Umsatz brachten, denn zunächst wurden Prüfstücke angefordert. So ging ein großer Teil der ersten Auflage kostenlos in die Lande. Bald aber verkaufte sich das Buch dann fast von selbst, und es mußte alle zwei bis drei Jahre eine neue Auflage gedruckt werden. 
Eounenburgs

\section{Granumuatif ber engliidfen Sprande}

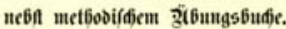

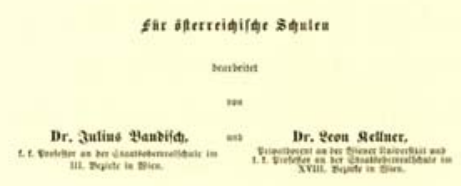

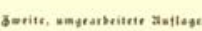

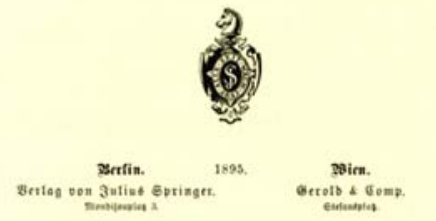

(6ram matik

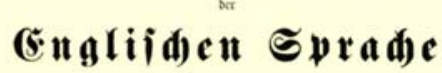

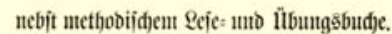
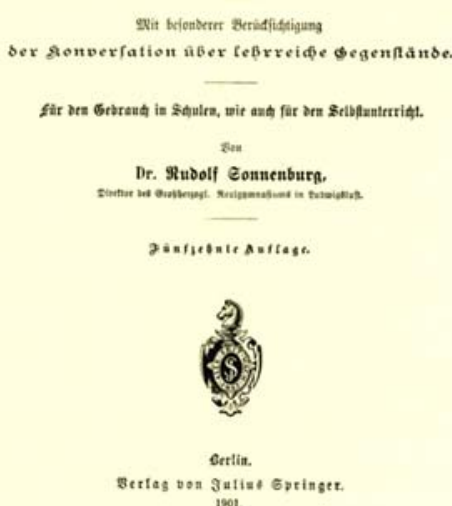

51: Rudolf Sonnenhurgs englische Grammatik war Springers erfolgreichstes Schulbuch. - 52: Seit 1889 erschien auch eine für österreichische Schulen bearbeitete Ausgabe, die vom k.k.Ministerium für Kultus und Unterricht approbiert war.

Eine mächtige Aufregung gab es, als 1876 ein Wiener Anglist die fünfte Auflage in der >Zeitschrift für das Realschulwesen< einer vernichtenden Kritik unterzog. Da der Rezensent selbst eine recht erfolglose englische Grammatik verfaßt hatte, war dem Verlag die Replik nicht gar zu schwer gemacht: In einem vierseitigen Rundschreiben für österreichische Realschulen druckte Springer zunächst die positiven Urteile über seine Ausgabe, vorwiegend von österreichischen Schulmännern, ab und würzte den Text dann mit einigen Kostproben aus dem Lehrbuch des gehässigen Rezensenten. Nicht zuletzt war es dieser Kampagne zu danken, daß seit 1889 auch eine österreichische Ausgabe des Sonnenburg erschien, die vom k.k. Ministerium für Kultur und Unterricht approbiert worden war.

Seit 1869 bekam der Schulbuchverlag erneut Auftrieb, nachdem Springer wieder in den Stadtrat gewählt worden war. Als Vorsitzender der Schulkommission wird er die sich hier bietenden Kontakte und Informationen genutzt haben. Auch sein Sohn Ferdinand nahm sich dieses Verlagszweiges nach seinem Eintritt in den Verlag (1871) mit besonderem Interesse an.

$\mathrm{S}$ chon im Jahr der Verlagsgründung hatte Springer einen Rathgeber in den verschiedensten Angelegenheiten der Ökonomie, der Haus- und Landwirtschaft< als Kommissionstitel in sein Programm aufgenommen. Dies war nicht ungewöhnlich, denn die Landwirtschaft gehörte auch in seiner Buchhandlung
Forst- und Jagdwesen.

Landwirtschaft 
Die (Srundjäzße

\section{Echå̋̉udbtuma.}

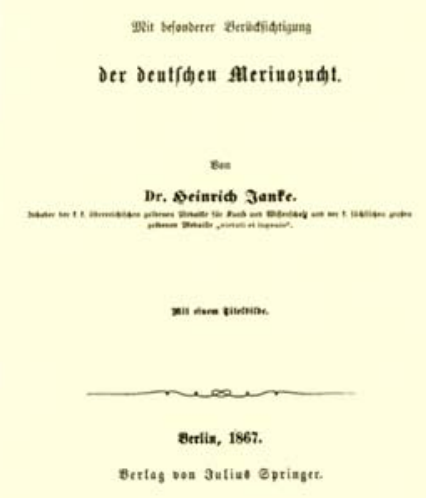

53: Die Zahl der landwirtschaftlichen Titel war zwar nicht so erheblich wie die für das Forst- und Jagdwesen, doch es waren durchweg gutgehende Bücher. zu den bevorzugten Fachgebieten. Es blieb aber zunächst bei Vereinzeltem; eine Verlagsplanung ist in dieser Richtung nicht zu erkennen. Bücher zur Hühnerzucht, die sich bald darauf im Programm finden, mögen durch Empfehlung in den Verlag gekommen sein; einige von ihnen erlebten sogar mehrere Auflagen.

Größere Beachtung verdient schon der seit 1860-verlegte Jahresbericht über die Fortschritte der Agricultur-Chemie mit besonderer Berücksichtigung der Pflanzenchemie und Pflanzenphysiologic<. Es war dies die erste Verlagsveröffentlichung, in der periodisch über Fortschritte cines Wissenschaftszweigs berichtet wurde. Nach dem Vorliegen des 22. Bandes (1880) überlicB Springer die Verlagsrechte am Jahresbericht seinem Berliner Kollegen Paul Parey.

$\mathrm{Zu}$ einer wesentlich größcren Bedeutung gelangte der forstund jagdwissenschaftliche Verlagsbereich. 1852 hatte Springer von Otto Spamer den 'Forst- und Jagdkalender für Preußen< zum alleinigen Vertrieb in Preußen übernommen, womit er nahezu die ausschlieBlichen Vertriebsrechte hatte. Absatz und Rentabilität entwickelten sich so günstig, daß Springer dieses lukrative Verlagsobjekt im Mai 1858 von Spamer erwarb. Der Verkauf des Sortiments hatte es ihm ermöglicht, den mit 1500 Talern nicht geringen Preis noch im selben Jahr bar zu bezahlen. ${ }^{14}$

Nach dem Erwerb des Kalenders begann Springer, die Forstwissenschaft systematisch zu einem eigenen Verlagszweig auszubauen. Es war dies seine erste fachwissenschaftliche Spezialisierung. Sie erfolgte zum rechten Zeitpunkt, denn es wurden damals Erkenntnisse aus der Agrarchemie, der Bodenkunde, der Zoologie, der Botanik und auch der Ökonomie für die Forstwirtschaft nutzbar gemacht; dabei wurde auch bereits die Ansicht vertreten, daß die Wälder nicht weiterhin bedenkenlos durch den Einschlag von Bau- und Brennholz ausgebeutet werden sollten, sondern als Lebensraum des Menschen des Schutzes und der Pflege bedürften. Es ist also in Ansätzen schon ökologisches Denken zu erkennen, wenngleich ökonomische Überlegungen noch im Vordergrund standen: Für das sich rasch ausdehnende Eisenbahnnetz, für den Bergbau und für die Papierherstellung benötigte man immer mehr Nutzholz, und da ein Großteil der Forsten staatlich war, spielten auch fiskalische Überlegungen eine gewisse Rolle.

Preußen hatte - außer einigen unselbständigen Universitätsinstituten - zunächst nur eine Forstakademie in NeustadtEberswalde, etwa 50 Kilometer nordöstlich von Berlin. In den übrigen deutschen Staaten gab es, neben der berühmten Aka- 


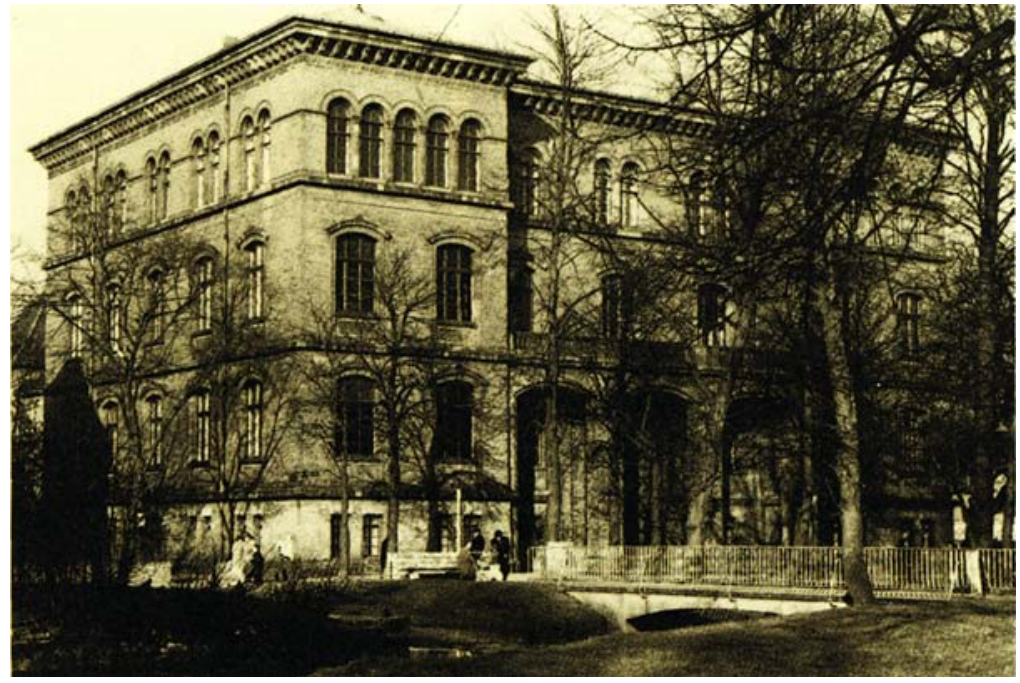

demie in Tharandt, noch Lehrstätten in Aschaffenburg und Eisenach. Zur vollständigen Ausstattung einer Akademie gehörten, neben drei forstwirtschaftlichen Lehrstühlen, auch Rechtskunde, Staatwissenschaften, Mathematik, Geodäsie, Physik und Chemie, Mineralogie und Gesteinskunde sowie Forstbotanik und-zoologie. Mit diesem Hinweis wird verständlich, daß in diesen Jahren manches naturwissenschaftliche Buch des Springer-Verlags noch von Forstakademielehrern geschricben wurde.

Der Herausgeber des $>$ Forst- und Jagdkalenders $<$, Friedrich Wilhelm Schneider, lehrte fast 50 Jahre in Neustadt-Eberswalde. Es spricht für die wachsende Bedeutung der Forstwissenschaft und für die Tüchtigkeit von Schneider als Herausgeber, daß sich der Umfang des Kalenders während seiner über 20 Jahre währenden Herausgeberschaft mehr als verdoppelte, und daß der Kalender seit 1873 unangefochten den Titel $>$ Forst- und Jagdkalender für das Deutsche Reich führte.

Durch Schneider kamen auch andere Professoren der Akademie zu Springer, so der Forstzoologe Bernard Altum und Bernhard Danckelmann, der seit 1866 Direktor der Anstalt war. Seit 1867, als in (Hannoversch-)Münden eine zweite preußische Forstakademie gegründet wurde, kam auch deren Direktor August Bernhardt mit wichtigen forstwirtschaftlichen Büchern zum Verlag.

1861 gründete Springer die >Forstlichen Blätter<, seine erste wissenschaftliche Zeitschrift auf eigenes Risiko. Die Voraussetzungen schienen günstig zu sein: Julius Theodor Grunert, der Direktor der Eberswalder Forstakademie, hatte die Herausgeberschaft übernommen, und Fachlehrer der Schule gaben dem
54: Die Forstakademie war 1830 von Berlin nach Neustadt-Eberswalde verlegt worden. Sie fand hier zunächst in einem Gebäude Unterkunft, das der Berliner Bankier David Schickler erworben hatte. Das hier abgebildete Rote Gebäudes wurde 1873-1876 errichtet. 
55, 56: Julius Theodor Grunert (1809-1889), bis 1866 Direktor der Forstlehranstalt, und sein Nachfolger Bermhard Danckelmann (1831-1906). Beide waren sehr rührig als Autoren und Herausgeber für Springers Verlag.
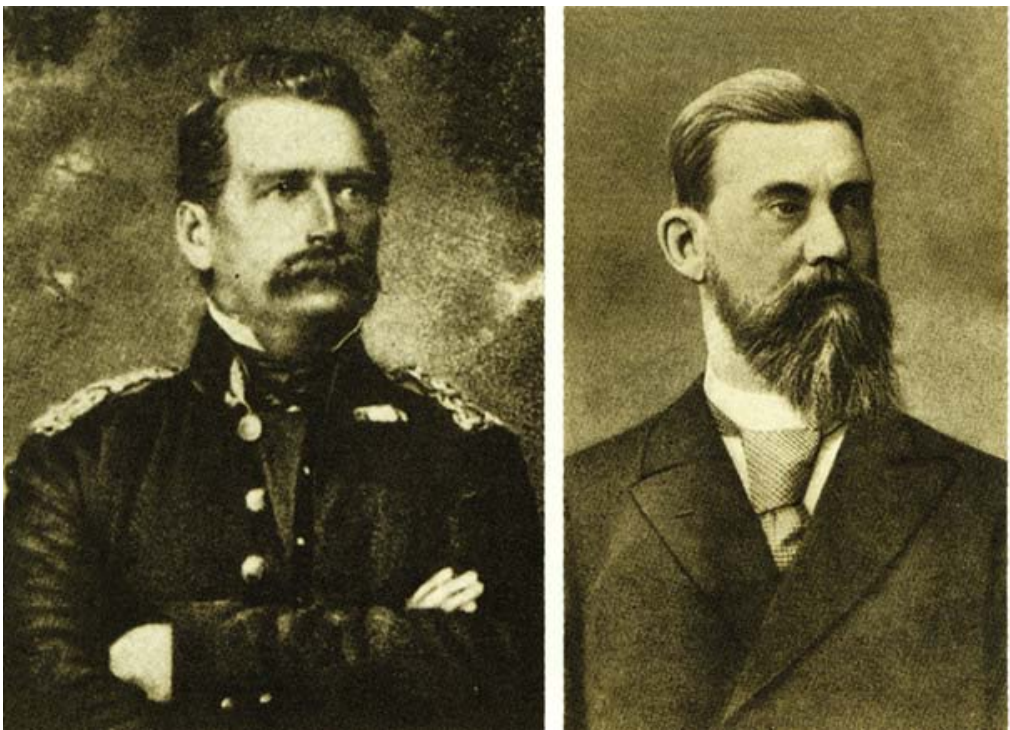

Blatt ihre Aufsätze. Doch die Zcitschrift fand keinen rechten Zuspruch, und Springer stellte sie 1867 ein. Als er dann 1869 mit Bernhard Danckelmann, dem Nachfolger von Grunert in Eberswalde, die >Zeitschrift für Forst- und Jagdwesen < gründete (dies war der Untertitel der ,Forstlichen Blätter< gewesen), stellte sich der Erfolg ein.

Gleichzeitig mit der erneuerten Zeitschrift erschien, ebenfalls von Danckelmann herausgegeben und von Schneider redigiert, ein >Jahrbuch der Preußischen Forst- und Jagdgesetzgebung und Verwaltung . Im bibliographischen Sinn war auch dies eine Zeitschrift, denn es erschienen jährlich zwei bis vier Hefte, die auch zu einem ermäßigten Preis, zusammen mit der $>$ Zeitschrift für Forst- und Jagdwesen<, bezogen werden konnten. Beide Periodika waren jahrzehntelang erfolgreich und wurden zu einer wichtigen Stütze von Springers forstwirtschaftlichem Verlag.

Daß es Springer dann 1874 gelang, auch den jährlich erscheinenden $>$ Bericht über die Versammlung deutscher Forstmänner< in seinen Verlag zu übernehmen, erweist sein Ansehen unter den Forstmännern der Zeit. Er hatte mit diesen Periodika eine solide Basis am Markt der forstlichen Literatur. Der Kalender und die Zeitschrift boten eine günstige Gelegenheit zur regelmäßigen Anzeige und zur Rezension des ständig wachsenden Programms, mit dem Springer nun alle Forstmänner des Deutschen Reiches ansprechen konnte.

Zwischen 1858 und 1877 entwickelte sich das forstwissenschaftliche Programm (einige wenige landwirtschaftliche Titel eingeschlossen) zum stärksten Verlagszweig dieser Periode. 
$\mathrm{Z}$

u den ersten erfolgreichen Unternehmen Springers nach dem Verkauf des Sortiments gchörte eine pharmazeutische

Pharmazie: Die Domäne Zeitschrift; sic war auf diesem Gebiet sein erstes Verlagsobjekt. Am 1.6. 1859 hatte Springer dem Apotheker und pharmazeutischen Fachschriftsteller Hermann Hager (1816-1897) eine mündliche Vereinbarung bestätigt, nach der er den Kommissionsverlag der zu gründenden Wochenzeitschrift $>$ Pharmazeutische Centralhalle für Deutschland $<$ übernehmen werde. Hager verpflichtete sich zur Zahlung der Herstellkosten, Springer übernahm den Vertrieb und besorgte die Anzeigen. Von den 15 Groschen des Quartalspreises sollte Hager $91 \frac{1}{2}$ Groschen erhalten. Ein paar Tage später bedingte sich der Autor dann einen halben Groschen mehr aus für alle Abonnements, die im Postzeitungsdienst ${ }^{15}$ vertrieben wurden.

\section{他OSPECU \\ einer neuen pharmaceutischen Wochenschrift,}

welche unter dem Titel:

\section{Pharmaceutische Centralhalle}

fiir Đentidjlano.

llerausgegelien von

Dr. Hermann $\mathrm{Hager}$.

vom 1. Juli d. J. an erocheinen wird.

Diese Wochenschrift, zu deren IIerausgabe ich von vielen Seiten dringend aufgefordert bin, stellt sich die $A$ ufgabe, der pharmaceutischen Genossenschaft Deutschlands ununterbrochen die Fortschritte in den verschiedenen Wissenszweigen, welche die Pharnacie berühren oder für diese von Interesse sind, vorzuführen und davon, wo es nöthig ist, auf kritischem oder analytischem Wege interpretirt zu Zwecken der Pharmacic soviel als möglich nutzhar zu machen. Die pharmaceutische Centralhalle wird zu dem Ende über den Inhalt sämmtlicher pharmaceutischen Journale des In - und Auslandes Berichtı bringen und die für die Pharmacie von Wichtigkeit erscheinenden Artikel im Aus. zuge oder mit den nöthizen Interpretationen begleitet dem Leser vorfüluren, auch den neusten Erzeugnissen der pharmacentischen Litteratur, so wie auch derjenigen aus den Wissenszweigen, welche die Pharmacie auf ihrem Wissens. felde nöthig hat, ihre volle Aufmerksamkeit zuwenden, und mit Anfuhrung des Wichtigsten der Kritik unterwerfen.

Im gleichen Maasse wird die pharmaceutische Centralballe die Verhältnisse und Interessen der praktisehen Pharmacie, dem Wesen derselben nach als Kunst, so wie in ihrer moralischen und geschäftlichen Stellung nach allen Soiten hin zu unterstützen suchen und das Material ansammeln, um auf der einen orler der anderen Seite den Fortschritt zu fördern. Sie wird rechtliche lBezichungen, wo solche fehlen oder nöthig werden, anzubahnen bebülflich scin und auch nach Krüften zu ermöglichen suchen. Die Nothwendigkeit hierzu dürfte demjenigen, welcher die angedeuteten Verbältnisse der Pharmacie zu würdigen weiss und die Beeinträchtigungen und Gefabren kennt, welche den selbstverständlichen Rechten des pharmaceutischen Standes bald hier bald dort erwachsen, nicht entgehen.

Ferner bleibt auch den Pharmaceuten, nicht allein in ihrem eigenen Interesse, sondern auch zu Nutz und Frommen des Publikums die Aufgabe, dem Geheimmittelunwesen zu steuern, und zwar genaue Aualysen diescr Geheimnittel zu liefern und unter Benutzung von gemeinnützigen Volksblättern die Gelieinmittel an den Pranger zu stellen, so wie auch bei den Aufsichtsbehörden den nöthigen Schutz aufzusuchen. Indem der von unserem geschätzten Frickhinger eingeschlagene Weg weiter zu verfolgen wäre, bietet die Redaktion der phar-

57: Seit dem 1.7.1859 erschien Springers erste pharmazeutische Zeitschrift. Den Prospekttext hatte der Herausgeber Hermann Hager geschrieben. 
58: Eine Abbildung aus Hagers Das Mikroskop, ausgeführt in Holzstich. 1932 erschien die 14. Auflage, bearbeitet von Rudolf Tobler.

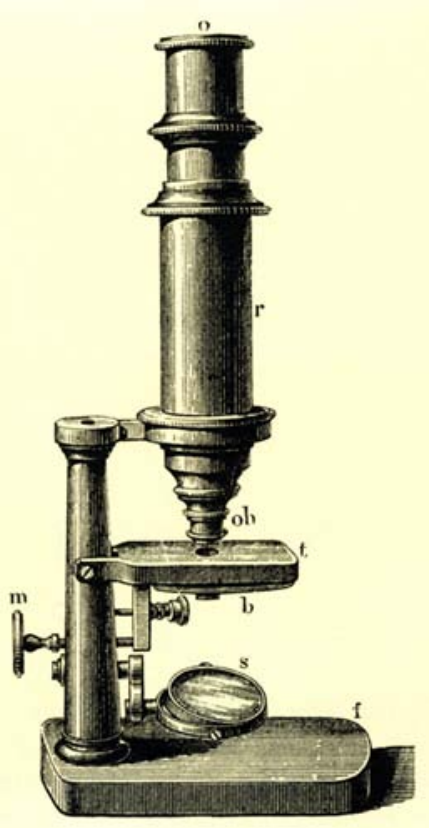

Springer hielt in seinem Vertragsbrief vom 1.6. 1859 weiterhin fest: »Wir vereinbarten ferner, daß, wenn irgendeine Differenz oder ein Streit entstehen sollte, wir ausdrücklich auf jeden gerichtlichen Entscheid verzichten [und] uns vielmehr dem Ausspruche des zu diesem Behufe bestehenden Ausschusses der Berliner Buchhändlercorporation unweigerlich unterwerfen.« Man darf also davon ausgehen, daß zwischen Autor und Verleger von Anbeginn cin vertrauensvolles Verhältnis bestand.

Mitte Juni 1859 verschickte Springer fast 2000 Prospekte und bot die kostenlose Licferung des ersten Heftes an. Der Buchhändlerpreis bei Barbezug betrug $11 \frac{1}{2}$ Groschen, so daß Springer je Quartalsabonnement 2 Groschen blicben. Den eigentlichen Profit sollten die Anzeigen bringen. Schon ein Vierteljahr später konnte er Hager berichten, daß mehr als 300 Exemplare abonniert worden seien; »so darf ich das Unternehmen als gesichert und fortgehend ansehen « (10.9.1859).

Wer heute eine Zeitschrift gründet, wird sich mit einiger Phantasie und mit Beziehungen, die auch der Herausgeber herstellen kann, die Anschriften möglicher Interessenten beschaffen können. Welche Probleme die Beschaffung von Adressen in jener Zeit aber bereitete, als selbst die Vereinigung von Fachleuten einer Berufsgruppe noch mit Schwierigkeiten verbunden war (es hätten politische Ziele verfolgt werden können!), zeigt ein Brief Springers an den Juniorpartner seines Lcipziger Kommissionärs Volckmar. Springer hattc Carl Voerster gebeten, ihm ein Verzeichnis mit den Anschriften aller Apotheker des Königsreichs Sachsen zu besorgen. Ein solches gebe es nach dem neuesten Stand nicht, mußte er nun erfahren, doch Vocrster teilte ihm mit, er habe »an einen Freund nach Dresden geschricben, welcher versuchen will, eine Abschrift vom Ministerium zu bekommen.... Die Arbeit des Abschreibens ist nicht groß, denn es gibt in Sachsen im Ganzen nur 180 bis 182 Apotheken $\ll$.

Es war also noch recht zeitaufwendig, das Adressenmaterial für die Bekanntmachung der neuen Zeitschrift zu beschaffen, doch die Mühe lohnte sich bald. Schon 1861 gründete Springer mit Hager einen $>$ Pharmazeutischen Kalender für Norddeutschland ( seit 1872 >für das Deutsche Reich $<$ ) und ein >Pharmazeutisches Jahrbuch «. Im nächsten Jahr übernahm er aus Hagers früherem Verlag Günther in Lissa (später Breslau) die Rechte an der >Technik der Pharmazeutischen Rezeptur< und verlegte das Buch in der 3. und in allen folgenden Auflagen. Hagers > Das Mikroskop und seine Anwendung. Ein Leitfaden bei mikroskopischen Untersuchungen für Apotheker, Ärzte, Medicinalbeamte, Kaufleute, Techniker, Schullehrer, Flcischbeschauer 
etc. $<$ - man beachte die Berufsgruppenprozession im Untertitel - erschicn 1866 und blicb in immer wieder erneuerten Auflagen über 70 Jahre lang im Programm des Springer-Verlags. 1868 erschien Hagers > Erster Unterricht des Pharmaceuten in 92 Lektionen<, ein stattliches Werk von 500 Seiten mit $176 \mathrm{Holz}-$ stichen, das im Laufe der Jahre ständig erneuert und erweitert wurde.

So hatte Springer für das Gebiet der Pharmazie cine Zeitschrift, einen Kalender, ein Jahrbuch, ein Praktiker- und ein Lchrbuch, und all dies hatte ihm ein Autor geschrieben. Zehn Jahre lang bestritt Hager mit seinen Publikationen Springers pharmazeutischen Verlag. Erst $1869 \mathrm{kam}$ als erster >fremder< Autor der Apotheker Fritz Elsner mit einem > Grundriß der pharmazeutischen Chemie< hinzu. Anders also als in der Forstwissenschaft bemühte sich Springer offenbar nicht um weitere Literatur auf dem Gebiet der Pharmazie. Mit der Forstakademic Eberswalde, später auch Münden, hatte er sich Institutionen verbunden, zu deren Lehrkörper cr Kontakte vielfältiger Art herstellen konnte, während Hager ein Einzelgänger war, der Springer wohl kaum Hinweise auf den Ausbau des Programms gegeben hat. Er wollte sein Revier nicht mit anderen teilen.

Erst seit 1871, also mit dem Eintritt von Ferdinand Springer, kamen weitere Autoren hinzu. Und der Junior genierte sich auch nicht, Hager Manuskripte anderer Pharmazeuten zur Begutachtung zu schicken. Hagers Sohn Arnold war mit Ferdinand Springer bcim gleichen Regiment an den Kämpfen in Lothringen beteiligt gewesen, und die Väter hatten stets Nachrichten über das Ergehen ihrer Söhne ausgetauscht. So etwas verbindet auch im Verlagsgeschäft.

Hager blieb in scinem kaum zu überbietenden Fleiß aber weiterhin Springers Hauptautor: Von 1872 bis 1874 erschien sein >Commentar zur Pharmacopoea Germanica< in 21 Licferungen

59: Ausschnitt aus Hagers Versicherungsantrag bei der, Coloniac. Der Verleger wollte sich für den Fall absichern, daß sein Autor vor Abschluß der Arbeit stürbe (s.S.69).

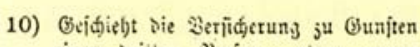
ciner oritten \&erion, etra regen Eduloiorberung?

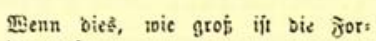
berung?

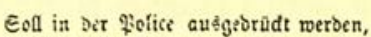

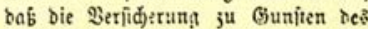
Eläubigers ex erfolgt ijt?

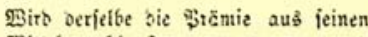
Ditte!n jab!en?

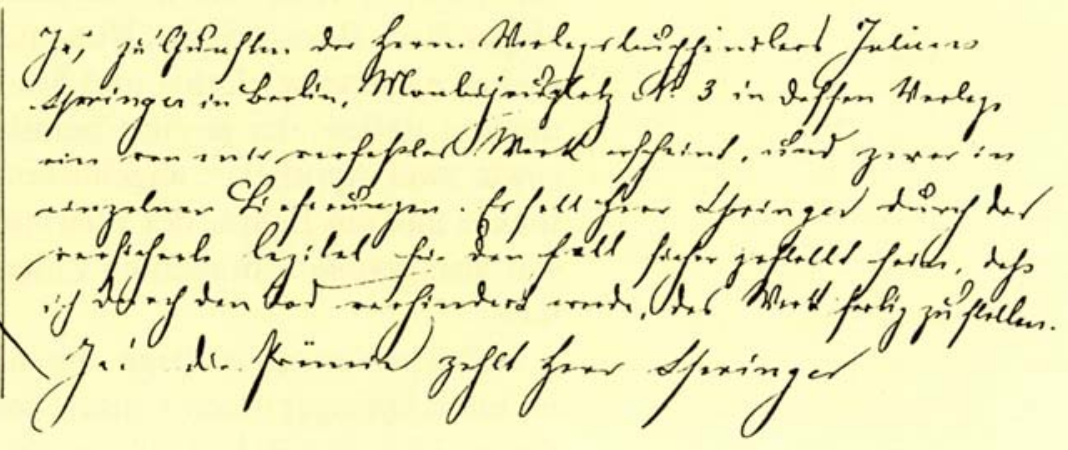


60, 61: Hermann Hager (1816 bis 1897), Julius Springers erfolgreichster wissenschaftlicher Autor. Der Stahlstich wurde dem 2. Band des Handbuchs vorangestellt, von dem bei Erscheinen der 1. Lieferung von Band 2 schon 3000 Exemplare verkauft waren.

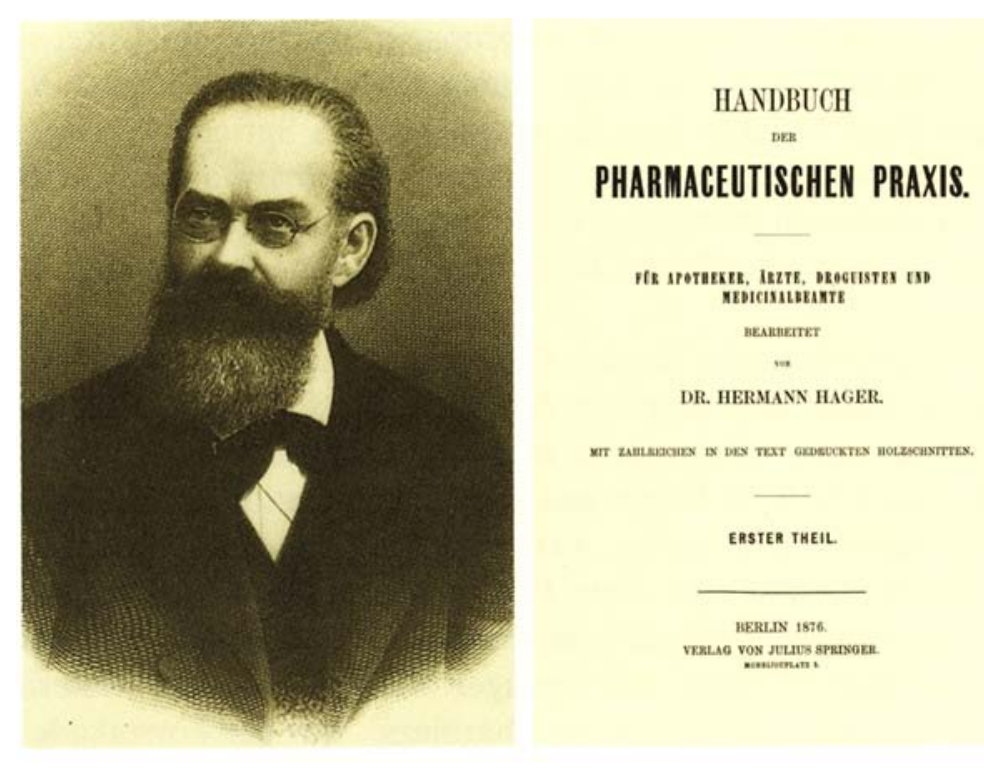

mit insgesamt 1700 Seiten. Ein Jahr später schlicßlich begann sein Opus magnum zu erscheinen, das > Handbuch der pharmazeutischen Praxis<. 1878, also ein Jahr nach Springers Tod, lag es mit der 22. Lieferung und fast 2600 Seiten komplett vor. Hagers Handbuch wurde Julius Springers größtes und erfolgreichstes Verlagswerk.

Autor und Verleger hatten sich auf cine Auflage von 3000 Exemplaren verständigt. Doch che 1876 die letzte Lieferung des ersten Bandes vorlag, war der Verkauf der Auflage schon abzusehen. Ab dem zweiten Band wurden dann 4000 Exemplare gedruckt und vom ersten Band mußten 1000 Exemplare sofort nachgedruckt werden. (Matern hatte der Verlag vorsorglich herstellen lassen.) Wie war dieser Erfolg möglich? Ein Jahr zuvor war für das Reichsgebiet eine Prüfungsordnung für Apotheker eingeführt worden, die ein dreisemestriges Studium voraussetzte. Zur Ausübung des Berufs hatte bis dahin noch eine dreijährige Lehrzcit und eine mindestens so lange >Servierzeit< genügt [ADLuNG: 143]. So hatten noch Fontane, Liebig und Hager ihren Beruf erlernt. Nun mußte sich der angehende Apotheker nach seiner Lehr- und Studienzeit einer Prüfungskommission stellen, der je ein Chemiker, Botaniker und Physiker sowic zwei Apothcker angehörten. (Es konnte auch ein Apotheker und ein Lehrer der Pharmazie sein.) Hagers Handbuch war also gerade zum rechten Zcitpunkt auf den Markt gekommen.

Mit dieser ersten Auflage, die in Licferungen 44 Mark kostetc, hatte Springer einen Umsatz von etwa 130000 Mark erziclt. Das war für jene Zeit ein überwältigender Erfolg. Dem standen 
jedoch auch entsprechend hohe Aufwendungen gegenüber: So hatte Hager 25000 Mark an Honoraren erhalten (das waren $14,2 \%$ vom Ladenpreis), und die Herstellkosten betrugen schätzungsweise 60000 Mark. Einen hohen Anteil hatten hicran dic zahlreichen Holzstiche, für die Hager die Vorlagen geliefert hatte, denn er war nicht nur ein guter Schreiber, sondern auch ein talentierter Zeichner.

Wie hoch Springer seinen Autor schätzte, und wie sehr es auch Hager bewußt war, daß nach scinem Tod kein gleichbedeutender Autor das Werk hätte zu Ende führen können, zeigt eine recht ungewöhnliche Vorsichtsmaßnahme: Hager schloß 1875 zugunsten Springers (und auf dessen Kosten) eine Lebensversicherung über 15000 Mark ab mit der Begründung, »es soll Herr Springer durch das versicherte legibel für den Fall sichergestellt sein, daß ich durch den Tod verhindert werde, das Werk fertigzustellen.«(Abb. S. 67).

Hager überlebte seinen Verleger um 20 Jahre. Als dieser schon schwer erkrankt war, empfahl er ihm am 20.3.1877 Chinin und Eisen, doch von der Wirkungsamkeit seines Medikaments war er wohl selbst nicht so recht überzeugt, denn er fügte hinzu: "Schaden machen sie nie! « Aber auch Hagers Therapie konnte Springer nicht mehr helfen.

A nfang Mai 1848 wurde Springer zum ersten Mal in den Berliner Stadtrat gewählt, der damals 102 Abgeordnete zählte. Außer zehn Buchhändlern, unter ihnen auch der mit Springer befreundete Verleger Moritz Veit, begegnete er hier vielen ihm aus der politischen Szenc schon bekannten Persönlichkeiten, dic er später für seinen Verlag zu gewinnen verstand. Bei der konstituierenden Versammlung wurde Springer zum Schriftführer gewählt und war damit zugleich der Stellvertreter des Vorsitzenden. Nach der Auflösung der Berliner Abgeordnetenversammlung 1851 wurde Springer zu den Neuwahlen nicht mehr zugelassen.

1869 wurde Springer erncut für sieben Jahre in die Stadtverordnetenversammlung gewählt und gehörte während dieser Zeit verschiedenen Ausschüssen an, so der Geldbewilligungsdeputation - dem heutigen Haushaltsausschuß vergleichbar und der Schulkommission. Im November $1876 \mathrm{kam}$ er für den 25. Stadtbezirk wiederum in den Stadtrat und wurde einstimmig zum Stellvertreter des Vorsitzenden gewählt. Eine Aufforderung der Freisinnigen Partei, für die Wahlen zum Preußischen Landtag im Herbst $1876 \mathrm{zu}$ kandidieren, lehnte er allerdings ab [MS: 133f.]. Seiner Familie gegenüber äußerte er, es fehle ihm
62 (unten): Wolfgang Straßmann (1821 bis 1883), Berliner Stadtverordnetenvorsteher und Ehrenbïrger der Stadt, würdigte die Verdienste seines Stellvertreters nach dessen Tod. Die Stadtverordnetenversammlung hatte Springer noch während seiner schweren Krankheit erneut einstimmig zu Straßmanns Stellvertreter gewählt.

\section{Im Berliner Stadtrat}

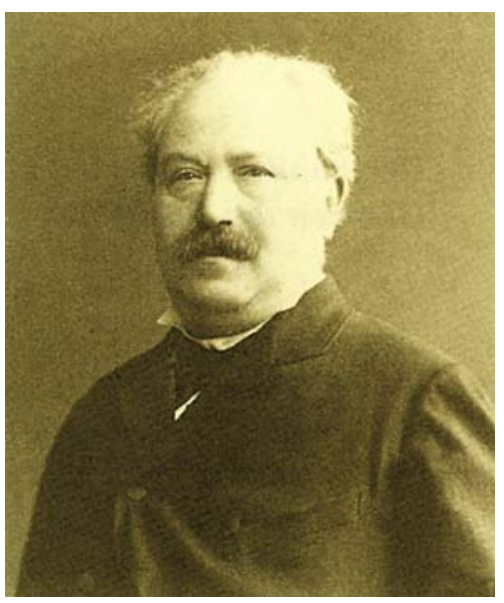


63: Finzug der preußischen Truppen nach dem deutsch-französischen Krieg am 16.6.1871. Springer stand mit dem Stadtrat zur Begriaßung am Brandenburger Tor, die Familie hatte auf der Tribüne Platz genommen. Unter den Soldaten war auch der Soln Fritz, der als Kriegsfreiwilliger am Feldzug teilgenommen hatte.

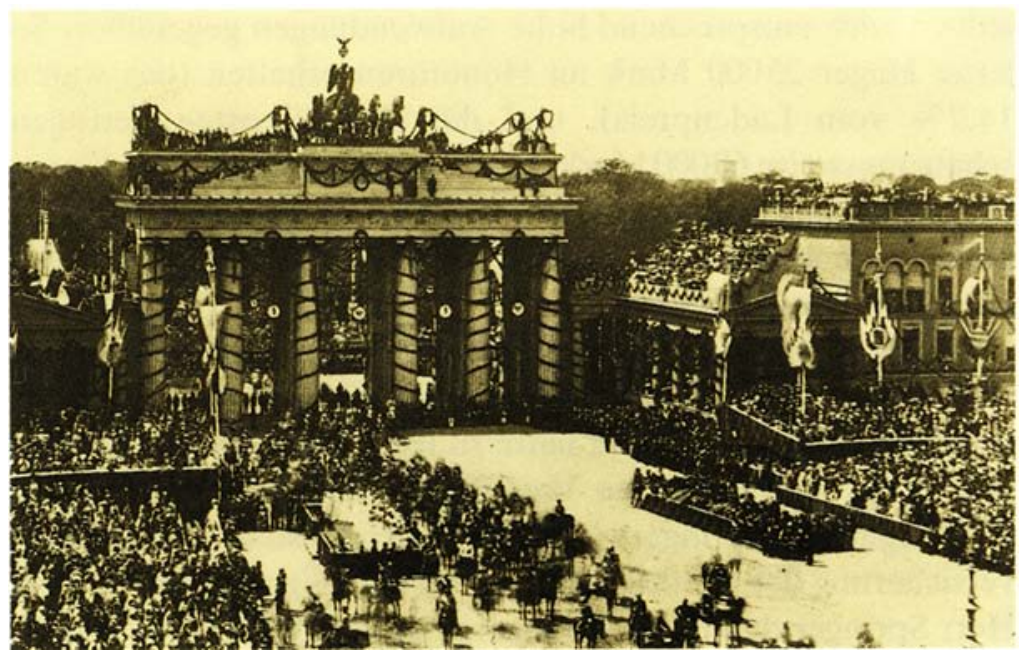

an Frische und an der Kraft, sich mit den neuen Aufgaben vertraut zu machen.

Der Stadtverordnetenvorsteher Wolfgang Straßmann würdigte bei der Versammlung am 19.4.1877 Springers Verdienste, indem er u.a. ausführte:

Alles, was dic Gemeinde anging, ergriff er mit einer fast leidenschaftlichen Hingebung. Er war ein gerechter und edel gesinnter Mann, der sich gedrungen fühlte, an seine öffentliche Tätigkeit den höchsten sittlichen Maßstab anzulegen und den übernommenen Pflichten mit strengster Gewissenhaftigkeit nachzuleben. Er war ein gerechter Mann, der jedes redliche Bemühen und jede aufrichtige Überzeugung ehrte und achtete. Er achtete aber auch seine eigene Überzeugung, welche er jeder Zeit unerschrocken, mit Ernst und Nachdruck zu verteidigen wußte. Über Allem aber stand ihm das Recht dieser Versammlung. Er hielt es für eine Gewissenssache, die gesetzliche Stellung dieser Versammlung vor jedem Schein und vor jeder Möglichkeit einer Beeinträchtigung und Schmälerung zu bewahren, das Ansehen und die Würde der Versammlung vor jeder Verunglimpfung und vor jeder Kränkung, soweit es in sciner Macht stand, zu schützen [MS: 165f.].

Der Publizist. Tätigkeit in Gremien des Buchhandels

$\mathrm{S}$ chon während seiner Gehilfenzeit war Julius Springer in den Blättern des Buchhandels publizistisch ungemein rührig gewesen. Es sind weit über 50 Beiträge nachzuweisen, doch die genaue Zahl dürfte wesentlich höher liegen, da Springer bis 1844 zunächst nur mit den Initialen oder schlicht mit einem $>\mathrm{S}$ < zeichnete. Da dies schon bekannt war - und der Anfangsbuchstabe seines Namens nicht gerade zu den seltenen zählt --, konnte es nicht ausbleiben, daß auch andere Autoren ihre Beiträge in gleicher Weise zeichneten. So wurden Springer - mit oder ohne besondere Absicht - Auffassungen zugeschoben, die 
er nicht geneigt war zu vertreten. Deshalb gab er am 24.5.1844 im Börscnblatt die »Notwendige Erklärung« ab: ... ich werde fortan alle von mir verfaßten und für diese Blätter bestimmten Artikel nicht mehr mit J. S. oder S., sondern mit meinem Namen oder mit deutlicher Hinweisung, daß sie von mir (stammen), unterzeichnen...«

Sein besonderes Interesse galt Fragen des Nachdrucks (auch ausländischer Autoren), den Pressegesetzen und der Zensur. Er hatte sich umfassende Kenntnisse gerade in Urheberrechtsfragen erworben und verstand diese auch zu vermitteln. Schon in dem 1847 gegen ihn angestrengten Prozeß (s. S. 27) war Springer neben seinen gründlichen juristischen Kenntnissen auch das rhetorische Geschick zustatten gekommen, mit dem er seine Auffassungen vertreten hatte. Wenn Marie Springer schreibt, oft habe ihr Mann es bedauert, nicht Jurist geworden zu sein [MS: 67], so wird man das gerne glauben. Die Beschäftigung mit Rechtsfragen war für ihn ein intellektuelles Vergnügen. Diese Neigung ist später auch bei seinen Söhnen und seinem Enkel Ferdinand zu beobachten.

In seinen Beiträgen beschäftigte sich Springer auch temperamentvoll mit allgemeinen Fragen der buchhändlerischen Praxis: Kommissionsbuchhandel, Portoberechnung, Währungsrechnungen und mit buchhändlerischer Fachliteratur. Es ist bezeichnend, daß er während der Vorbereitung seiner Etablierung die erste Licferung der >Praktischen Vorschule für den deutschen Buchhandel von Albert Höpstein, dem ersten um Systematik bemühten Fachbuch der Branche überhaupt, auf acht Spalten ausführlich und durchaus kritisch im >Börsenblatt $<$ rezensierte (15.3.1842). Sicherlich haben Springers publizistische Beiträge, insbesondere im Börsenblatt, nicht unwesentlich zu seiner Reputation unter Fachgenossen beigetragen. Wie sehr man seine Beiträge schätzte, zeigt auch ein Brief von Julius Krauß, dem Chefredakteur des Börsenblatts, vom 2.3. 1866, in dem dieser schreibt: »Warum lassen Sie denn dem Börsenblatte ihre gewohnten und geschätzten Beiträge nicht mehr zukommen? So vermisse ich namentlich in der gegenwärtigen brennenden Tagesfrage, der Börsenblatt-Reform, schmerzlich cine Meinungsäußerung von Ihnen. Ich habe die Abfassung des Referats, das mir über den Gegenstand aufgetragen ist, bis jetzt noch unterlassen, weil es für mich von besonderem Werte ist, erst noch Ihre Ansichten kennenzulernen.«Für Springers Zurückhaltung in diesen Jahren spricht einmal seine zcitabsorbierende Tätigkcit im Berliner Stadtrat, zum anderen wohl auch, daß er ahnen mochte, mit diesen Fragen sehr bald von Amts wegen konfrontiert zu werden.

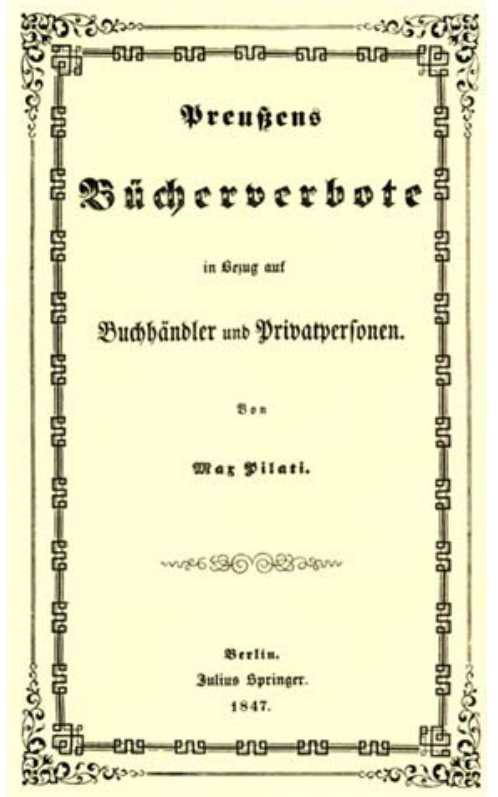

64: Schon in den 1840er Jahren hatte Springer ein erstes Buch zum Recht des Buchhandels veröfentlicht. 
Im November 1848 war Springer unter den Gründungsmitgliedern der $>$ Korporation Berliner Buchhändler<, deren Vorstand er 26 Jahre lang angchörte. Seinem juristisch geschulten Verstand dankte er 1862 auch die Delegicrung in den seit 1837 bestehenden >Litcrarischen Sachverständigen-Verein<.

Im Leipziger Börsenverein gehörte Springer verschiedenen Ausschüssen an, so von 1856 bis 1859 und erneut von 1864 bis 1867 dem Vergleichsausschuß und dem Unterstützungsverein der Deutschen Buchhändler, dessen Leitung er von 1871 bis zu seinem Tode innchatte. Vertraut mit allen Besonderheiten des buchhändlerischen Geschäfts, gewandt in freier Rede und geschätzt als Verfasser juristisch geschliffener Schriftsätze, hatte sich Springer den Respekt seiner Fachgenossen erworben.

Erster Vorsteher des Börsenvereins

A m Cantate-Sonntag 1867, es war der 19. Mai, wurde Springer zum Vorsteher des Börsenvereins gewählt. Marie Springer berichtet in ihren Erinnerungen [MS: 80]: » Mit großer Freude und gerechtem Stolze machte er mir sofort in wenigen Zeilen davon Mitteilung, dic mit den Worten beginnen > Diesen Brief schreibt Dir Dein soeben mit Einstimmigkeit zum Börsenvorsteher erwählter Mann.« Springer war gerade 50 Jahre alt geworden und scit 25 Jahren selbständiger Buchhändler. Bcider Ereignisse hatte man kurz zuvor im kleinen Familien- und Freundeskreis in einer bescheidenen Feier gedacht.

In Springers Vorsteherzeit von 1867 bis 1873 waren auch für den deutschen Buchhandel wichtige Entscheidungen zu treffen. In die ersten Monate seiner Tätigkeit fiel die Aufhebung der buchhändlerischen Konzessionspflicht und des Buchhändler-

65: Cantate-Essen 1870, als Springer gerade zum Ersten Vorsteher des Börsenvereins wiedergewählt worden war.

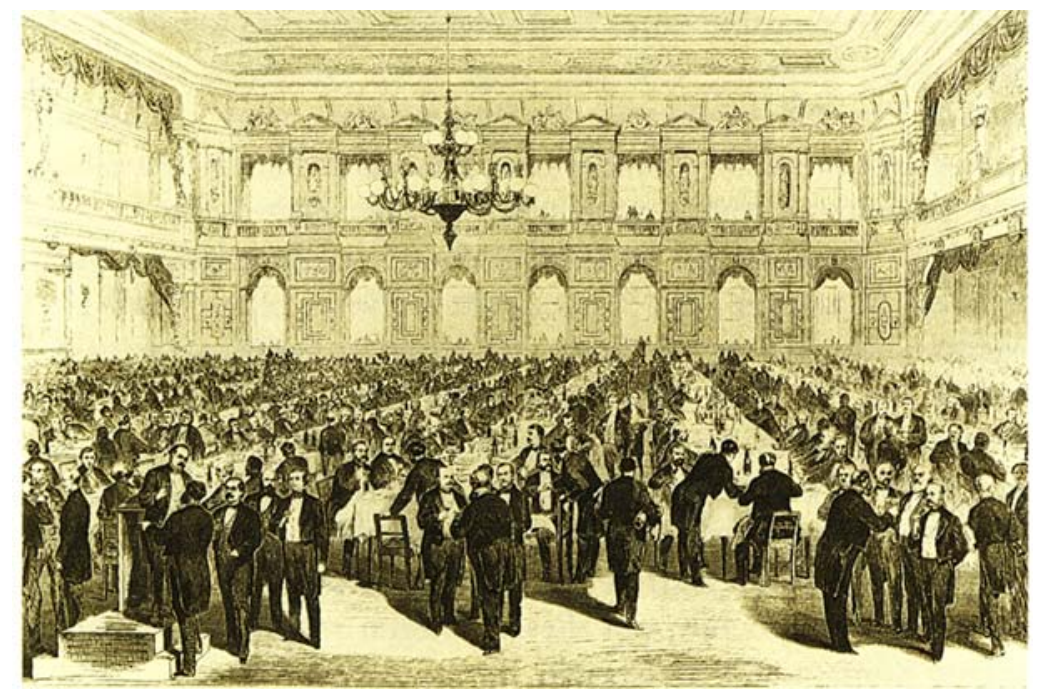


examens, dem sich seit 1851 Sortimenter in manchen Bundesstaaten hatten unterziehen müssen. Die Aufhebung der Konzessionspflicht war schon in cinigen deutschen Staaten durch die Gewerbefreiheit erfolgt, die nach der Gewerbeordnung des Norddeutschen Bundes am 21.6.1869 nun für fast alle Gewerbezweige galt. Es bedurfte also auch der Buchhändler künftig weder einer Konzession, noch hatte er in einer Prüfung seine Kenntnisse nachzuweisen. Dies führte durch den Zustrom unqualifizicrter Kräfte zu einer rapiden Ausweitung des Buchhandelsnetzes und damit zu ciner ticfgreifenden Gefährdung traditioneller Handelsbräuche. Es begannen für den Buchhandel turbulente Zeiten.

Dic crhöhten Aktivitäten im deutschen Buchhandel während Springers Vorsteherschaft sind am fast sprunghaften Anschwellen des Fachblattes zu erkennen: 1866 hatte der Umfang des >Börsenblatts 2800 Seiten betragen, 1872 waren es fast schon 5000 Seiten. Zugenommen hatten aber nicht nur die Werbeanzeigen und Personalannoncen. Auch der redaktionelle Teil beanspruchte mehr Raum, zumal Springer Sitzungen des Vorstands auch zwischen den Messen eingeführt hatte. Doch nicht nur die Berichte hierüber und dic sich anschließenden Kommentare und Diskussionen füllten die Spalten des redaktionellen Teils in stärkcrem Umfang, sondern auch Fachartikel allgemeiner Art, für die Springer bei entsprechender Qualität die Zahlung von Honoraren durchgesetzt hatte. Seine besondere Förderung erfuhren dabei Arbeiten zur Geschichte des deutschen Buchhandels. Springer sorgte auch für einen regulären Etat der Vereinsbibliothek, kümmerte sich um deren Aufstellung und veranlaßte die Bearbeitung und den Druck des ersten Bibliothekskatalogs, der zur Ostermesse 1869 erschien.

Eine ins Einzelne gehende Darstellung von Springers Verdiensten um seinen Berufsstand während dieser Zeit würde den Rahmen dieser Darstellung sprengen, zumal es sich in einigen Fällen um Neucrungen im Börsenverein und seinen Institutionen handelte, die heute nur noch für einige Fachkollegen von Interesse sind. Es sei an dieser Stelle nur auf einige Änderungen in den Posttarifen hingewiesen, die 1867 nach der Ablösung des Postprivilegs von Thurn und Taxis durch den preußischen Staat eintraten. Springer erreichte durch seine guten Kontakte zu Heinrich Stephan, dem genialen preußischen Generalpostmeister und Initiator des Weltpostvereins, einige wesentliche Gebührenverbesserungen für den Buchhandel. So wurde 1871 ein Portosatz von 3 Pfennig für Bücherbestellungen in Postkartenform eingeführt, ${ }^{16}$ der so preisgünstig war, daß er den direkten

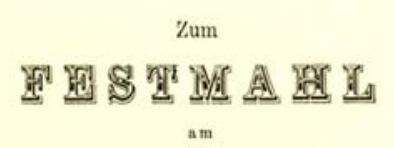

19. Mai 1867.

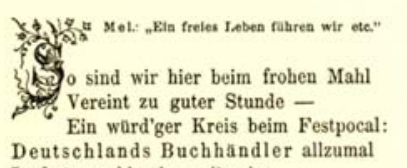
Deutschlands Buchhandler allzuma In fest geschloss'nem Bunde.

Durch uns ist Deutschland längst schon Eins, So weit wir Deutsch uns nennen,

Vom Niemen bis zum Strand des Rheins; Und keine „Linie des Mains"

Mag diese Einheit trennen.

Auf unsrer Tenne wird die Saat

Des deutschen Geists gedroschen

Wetteifernd drischt, wer Krafte hat; Und dieses Eifers Resultat

Ist: - Schiller zu vier Groschen!

Es sind des Geistes Waff und Wehr Der Freiheit beste Statzen.

Ob noch so stark der Feind auch wăr',

Wir liefern fur das Fortschritts-Heer Die ächten „Kugelspritzen."

So durfen wir auf unsern Stand Mit Stolz das Glas erheben.

Auf, auf! Den Becher jetzt zur Hand:

Hoch soll das Deutsche Vaterland,

Hoch sein Buchhandel leben!

66: Die deutschen Buchhändler verstanden sich als Schrittmacher der deutschen Einheit ( Durch uns ist Deutschland längst schon Eins"). Dieses Lied wurde gesungen, als Springer das erste Mal zum Vorsteher des Börsenvereins gewählt worden war. 
Kontakt zwischen Sortimentern und Verlegern wesentlich förderte. Die Gebühr war damit für manche Bestellungen vorteilhafter als der Verkehr über Leipzig. Auch die Erhöhung des zulässigen Gewichts für Streifbandsendungen von 250 auf 500 Gramm begünstigte den Postversand. Hiervon profitierten auch die Verleger bei der Direktlieferung von Zeitschriften an Privatkunden. Derartige Portoermäßigungen um wenige Pfennig mögen uns heute unerheblich erscheinen. Ihre Bedeutung versteht man besser angesichts der Tatsache, daß um 1870 noch über $60 \%$ aller Neuerscheinungen weniger als 1 Mark kosteten. Massenlektüre wie die Bände von Reclams Universal-Bibliothek kosteten z. B. nur 20 Pfennig, von denen dem Buchhändler also lediglich 5-6 Pfennig als Rabatt blieben.

Urheber-und Verlagsrecht

67: Der Verleger Moritz Veit (1808 bis 1864) war schon Anfang der 1840er Jahre mit Springer bekannt geworden. 1848 saßen beide im Berliner Stadtrat, von 1855 bis 1861 war Veit für zwei Perioden Vorsteher des Börsenvereins.

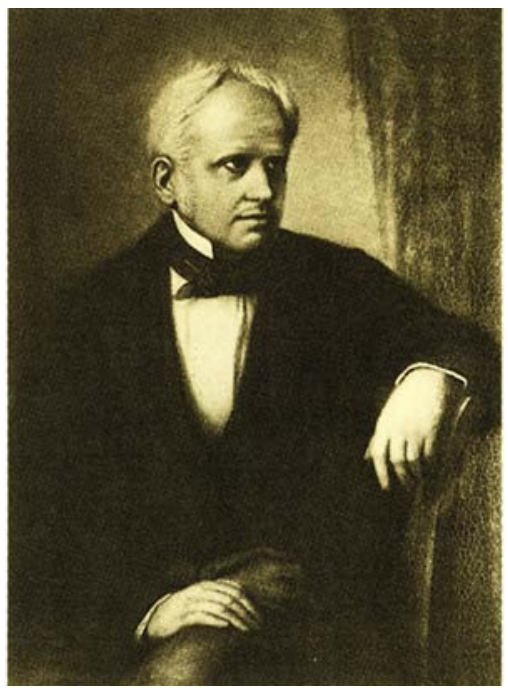

A m 8.11.1867 wurde die Aufhebung des sewigen Verlagsrechts $<{ }^{17}$ für die deutschen Klassiker wirksam. Springer, der hiervon in keiner Weise betroffen war, hob in seiner Rede auf der Hauptversammlung am 16.5.1868 besonders den urheberrechtlichen Aspekt hervor: »Das Jahr 1867 bildet für die Geschichte des deutschen Buchhandels einen bedeutsamen Abschnitt. Tatsächlich hat damit der von der deutschen Gesetzgebung festgestellte Grundsatz nun Platz gegriffen, daß das Autorrecht während des Lebens des Autors und darüber noch ein Menschenalter (30 Jahre) geschützt ist « [FrommanN: 44].

Wie schon manche seiner Amtsvorgänger, insbesondere der Berliner Freund und Kollege Moritz Veit, ein promovierter Jurist, der von 1855 bis 1861 Börsenvereinsvorsteher gewesen war, sah Springer seine Hauptaufgabe in der Sicherung und Verbesserung des Urheber- und Verlagsrechts. So berief er für den 11. bis 15.1.1869 einen Ausschuß zur Beratung des vom Bundeskanzleramt vorgelegten Gesetzentwurfes für ein neues Urheberrecht nach Leipzig ein. Er erreichte es auch, daß das damalige Bundeskanzleramt noch besonderere Kommissionssitzungen ansetzte, an welchen Juristen, Gelehrte, Künstler und Buchhändler teilnahmen. Das am 20.5. 1870 vom Reichstag des Norddeutschen Bundes schließlich verabschiedete Gesetz - es wurde nach der Reichsverfassung vom 16.4.1871 für das ganze Deutsche Reich verbindlich - befriedigte zwar nicht alle Erwartungen, doch es bedeutete gegenüber den früheren Verhältnissen mit ihrer Rechtsunsicherheit bzw. Rechtsungleichheit einen wesentlichen Fortschritt.

1870 wurde eine von W. Petsch im Auftrag Springers zusammengestellte Schrift über den Verlagsvertrag in den einzelnen deutschen Staaten vorgelegt und im Vorstand erörtert. Es war 
an der Zcit, auch die Rechtsverhältnisse zwischen Autoren und Verlegern zu regeln, da in den einzelnen Staaten noch sehr unterschiedliche Geschäftsbräuche zu beachten waren. Es sollte aber noch 30 Jahre dauern, bis an die Stelle landesgesetzlicher Vorschriften das >Reichsgesetz über das Verlagsrecht< vom 19.6. 1901 trat [Mothes: 93 f.; Ulmer: 383 ff.].

Gleichfalls 1870 - in diesem Jahr war Julius Springer für eine zweite Amtsperiode von drei Jahren zum Vorsteher gewählt worden - veranlaßte er auch eine >Zusammenstellung der Verträge zum Schutze des Urheberrechts zwischen Deutschland, beziehentlich dessen einzelner Staaten einerseits und Belgien, England, Frankreich und der Schweiz andererseits $<$. Bis dahin waren die Rechte deutscher Urheber (und Verleger) im Ausland noch nicht geschützt - und umgekehrt. (Wir crinnern uns der Warnung Springers an Gotthelf, daß seine Bücher nach dem geltenden Urheberrecht in Deutschland nicht geschützt seien.) Nur mit den genannten Staaten hatten inzwischen einige deutsche Regierungen, insbesondere Sachsens und Preußens, bilaterale Verträge über den Schutz der Urheberrechte ihrer Staatsbürger geschlossen.

Mit Schreiben vom 24.2.1871 hatte Springer das Bundeskanzleramt gebeten, künftige Verträge klarer und einheitlicher zu formulieren. Dort hatte man aber andere Sorgen, denn seit der Proklamation des deutschen Kaiserreichs in Versailles waren schließlich erst fünf Wochen vergangen, und der Krieg in Frankreich dauerte noch an. So gab man zunächst den Ball zurück und ersuchte den Börsenverein, scine Beanstandungen

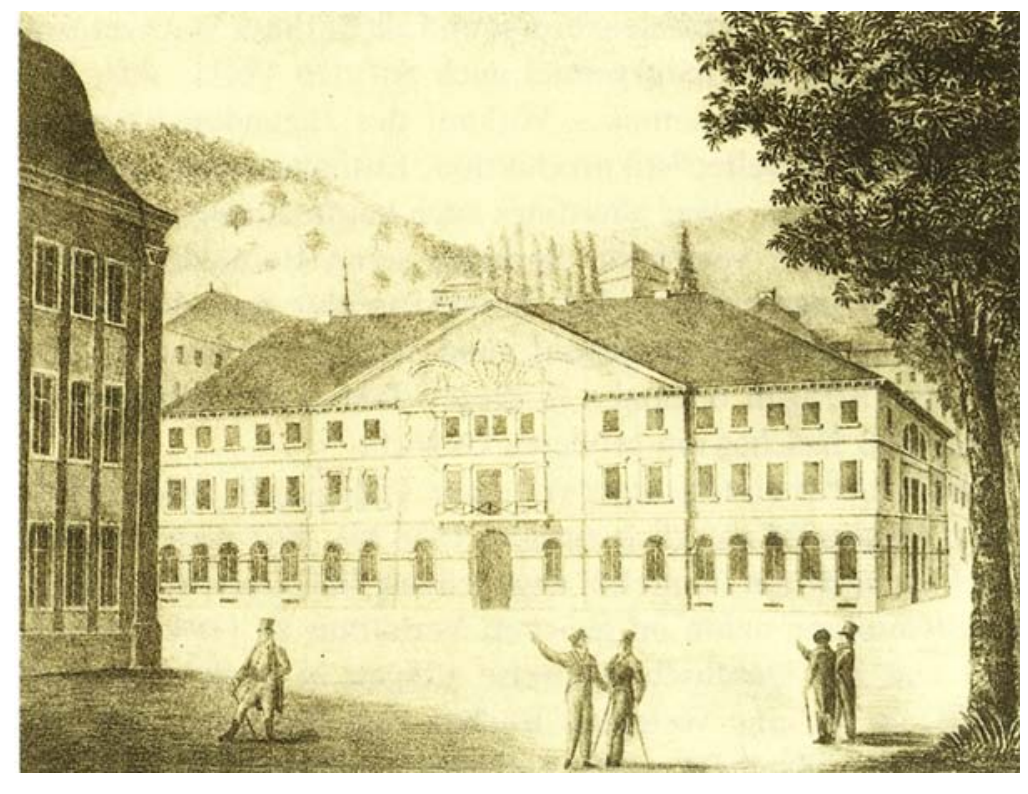

68: Im Heidelberger, Musäum fanden die Beratungen einer Expertenkommission unter Springers Leitung statt. Gegenstand der Erörterungen war der Entwurf eines Normvertrags mit ausländischen Staaten, der eine rechtliche Gleichstellung in- und ausländischer Autoren zum Ziel hatte. Der Bau diente seit 1904 als Kollegienhaus und wurde 1931 durch einen Neubau ersetz.t. Die Mittel für dessen Errichtung stammten aus Spenden von Deutsch-Amerikanern, für die der damalige amerikanische Botschafter in Berlin. Jacob Gould Schurman, geworben hatte. 
schriftlich darzulegen. Daraufhin berief Springer für den 4. bis 6.9.1871 cine Expertenkommission nach Heidelberg cin, an der sachkundige Vertreter des Verlagsbuchhandels - unter ihnen Härtel aus Leipzig, Rütten aus Frankfurt, Oldenbourg aus München, Ruprecht aus Göttingen und Winter aus Heidelberg teilnahmen.

Am letzten Verhandlungstag wurde dann eine Eingabe an das Reichskanzleramt aufgesetzt und der ausgearbeitete Entwurf cines > Normalvertrags < beigefügt. Daß diese Eingabe unbeantwortet blieb, lag wohl nicht zuletzt daran, daß die Verleger recht weit über den Auftrag hinaus gegangen waren. ${ }^{1 k}$ Es war wohl auch eine irrige Annahme, zu glauben, die Reichsregicrung könnte einen von deutschen Verlegern ausgearbeiteten Entwurf, der zudem nicht in allen Punkten dem geltenden deutschen Urheberrecht entsprach, als internationale Norm einführen. Ein Normvertrag hätte kaum die Uneinheitlichkcit des in den einzelnen curopäischen Ländern geltenden Urheberrechts überbrücken können.

Dic Konferenz hat aber langfristig dennoch ihre Wirkung nicht verfehlt. Vom 6. bis 9.9.1886, genau 15 Jahre später, einigten sich zunächst sieben europäische Länder auf dic sogenannte Berner Konvention, nach der Ausländer in den Vertragsstaaten urheberrechtlich den Inländern gleichgestellt wurden. ${ }^{19}$ Heute sind der Berner Konvention nahezu alle Staaten angeschlossen bzw. verbunden.

69: Aus Rudolf Herzbergs Buch: > Die Nähmaschine. Ihr Bau und ihre Benutzung`, Springer 1863.

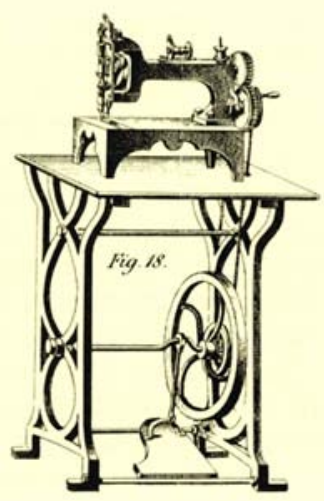

$\mathrm{D}$ ic zeitraubenden ehrenamtlichen Tätigkeiten als Erster Vorsteher des Börsenvereins und als Berliner Stadtverordneter wirkten sich naturgemäß auch auf den Verlag aus. Die Straffung des Programms - Verkauf des Jugendbuchverlags, Einstellen der Belletristikproduktion, Enthaltsamkeit bei politischen Schriften - war allerdings auch kaufmännisch von Vorteil. Schließlich verstärkte Springer seine Bemühungen um andere Verlagsbereiche: Die Forstwirtschaft und der Schulbuchverlag wurden ausgebaut, und Bücher zu Rechts- und Wirtschaftsfragen bekamen in diesen Jahren der Bildung des Deutschen Reiches ein größeres Gewicht.

Die Zahl der von Springer verlegten Titel ging in diesem Jahrzehnt insgesamt merklich zurück: 1858 bis 1867 waren es 437 Titel, im nächsten Jahrzehnt dagegen nur 363. Doch der Durchschnittsumfang nahm im gleichen Verhältnis zu (194:228 Seiten) und die Durchschnittspreise stiegen in noch stärkerem Maße, da die nun verlegten Bücher zum Teil sehr reich mit Holzstichen illustriert waren und damit naturgemäß einen hö- 
heren Preis hatten. In dieser Umstrukturierung lag sicher verlegerisches Kalkül; Springer konzentrierte sich auf Verlagszweige, die sich als rentabel erwiesen hatten.

$\mathbf{J}$ ulius Springer wurde von seinen Zeitgenossen eine bewundernswerte Arbeitskraft nachgesagt, doch diese hatte im letzten Jahrzehnt zunchmend dem Berufsstand und der Heimatstadt gegolten. So war es naheliegend, daß er im Frühjahr 1871 seinen ältesten Sohn Ferdinand in den Verlag aufnahm. Am Ende des Jahres machte er ihn schon zu seinem Teilhaber. Das für den Buchhandel vorbereitete Circular fand der 26jährige am Hciligabend unter dem Weihnachtsbaum.

Ferdinand Springer (21.7.1846-27.12.1906) war von lebhaftem Temperament. Als er erst 15 Monate alt war, hatte der Vater gegenüber Gotthelf schon kokett geklagt, »ich wünschte oft, der Bengel wäre dümmer und dafür dicker; aber in dem kleinen Geschöpf arbeitet schon ordentlich Geist und geistiges Belcbtsein...« (29.10.1847). Und zwei Monate später, am 3.1. 1848, berichtete er Gotthelf stolz, dic Leute meinten, der Junge sei »in Kopf und Wesen seinem Vater sehr ähnlich«.

Ferdinand war für den Verlag bestimmt, und der Heranwachsende hatte sich ganz auf seinen künftigen Beruf eingestellt. So setzte er es 1864 dem Vater gegenüber auch durch, dic Unterprima in Schulpforta verlassen zu dürfen, um eine Buchhandelslehre anzutreten. Sortiment und Verlag von Wilhelm Hertz boten eine vorzügliche Ausbildung, über dic cin Mitlehrling später ausführlich berichtet hat [КОСH]. Auf das Jahr als Einjährig-Frciwilliger beim Brandenburgischen Füsilierregiment Nr.35 folgten einige Monate Weiterbildung in der Buchhandlung von Carl Ed. Müller in Bremen - wo er überhaupt nicht heimisch werden konnte - sowic einige weitere Monate wieder bei Wilhelm Hertz, seiner Lehrfirma.

Im Herbst 1868 ging Ferdinand Springer für eine längere Gehilfenzeit in die Schweiz zur Dalp'schen Buchhandlung in Bern, mit deren Inhaber Karl Schmid ihn später eine lebenslange Freundschaft verband. Nach Ferdinand Springers Tod (1906) schrieb der Bruder Fritz an Alexander Francke, als dieser den Nachruf auf den Kollegen verfaßte: »Dic Berner Zeit lebte in Ferdinands Erinnerung wie mit einem Glorienschein umgeben. Wic oft hörte man ihn sagen: Ich bin ja ein halber Berner! « [Francke: VII]. Diese Liebe zur Schweiz hatte schon sein Vater gehegt, und sowohl für den Sohn Ferdinand d.J. als auch für den Urenkel des Gründers, Konrad Ferdinand, wurde die Schweiz zur Heimat ihres Herzens.
Ferdinand Springer

70: Wilhelm Ludwig Hertz. (1822 bis 1901$)$ gehörte zu den angesehensten Verlegern seiner Zeit. Mit Springer war er seit 1847 bekannt und später eng befreundet. Ferdinand Springer erlernte bei ihm den Buchhandel, die Tochter Emma Hertz heiratete 1879 Springers Sohn Fritz.

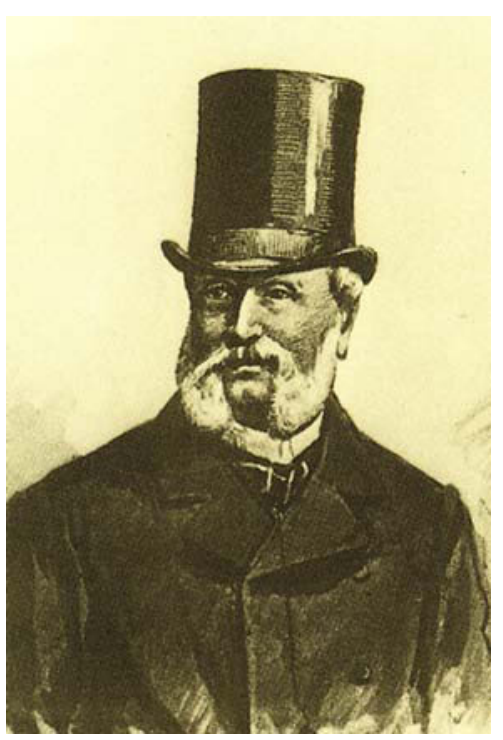




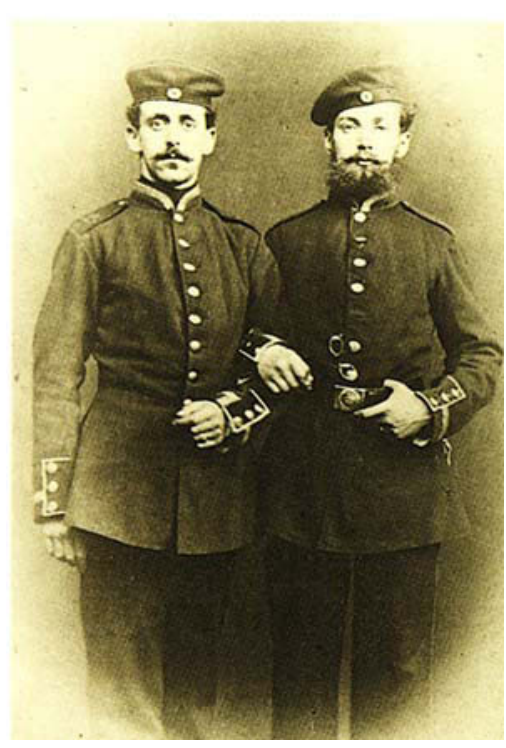

71: Ferdinand Springer (links) mit seinem Freund Hans Hertz. (1848 bis 1895), Sohn des Verlegers, 1870 in der Uniform des 35. Brandenburgischen Füsilierregiments.
Die Schweizer Zeit endete, als Ferdinand im Sommer 1870 bei drohender Kriegsgefahr nach Berlin zurückkehrte, um seiner Soldatenpflicht zu genügen. In Frankreich erkrankte er jedoch an Typhus, und dem Vater gelang es, ihn im Dezember zur Rekonvaleszenz nach Berlin zu holen [MS: 99f.]. Sobald er genesen war - es war dies spätestens im April 1871 - nahm er seine Tätigkeit im Verlag an der Seite des Vaters auf. »Ferdinands Persönlichkeit gefiel im Geschäft allen, mit denen er zu tun hatte«, erinnerte sich Marie Springer. Sein »zuvorkommendes, jugendliches Wesen machte guten Eindruck, und scine Arbeitskraft war, während des Vaters Zeit so vielfach von auBergeschäftlichen Dingen in Anspruch genommen war, nicht zu unterschätzen. So war, neben der Gunst der Zeit, gewiß auch ihm ein gutes Teil zuzuschreiben, wenn das Geschäft von dicsem Zeitpunkt an einen bedeutenden Aufschwung nahm « [MS: 109]. Diese Zäsur ist auch in der Zunahme der Produktion deutlich zu erkennen.

Wenn dem Junior auch schon wesentliche Aufgaben zufielen - es oblag ihm z. B. die Herstellung - so hatte sich der Vater doch die Geldgeschäfte vorbehalten. Als z. B. Hermann Hager, zu jener Zeit der wichtigste Verlagsautor, wieder einmal um Vorschuß nachgekommen war, konnte Ferdinand ihm nur schreiben: »Mein Vater, welcher die Kasse führt, ist augenblicklich in Leipzig « (25.3. 1873). Gleichwohl war er aber autorisiert, über cinen entsprechenden Betrag als Vorschuß zu verfügen.

Julius Springers letzte Jahre
$\mathrm{S}$ pringers 50. Geburtstag fiel auf den Tag, an dem er 25 Jahre zuvor seine Buchhandlung eröffnet hatte. Dies war Anlaß zu einer kleinen Doppelfeier im Kreise der Familie und einiger Freunde, bei der Wilhelm Hertz die Verdienste Springers in einer Tischrede würdigte: »Mit lebhaftem Auge und mit hellem Verstande blickten Sie umher und ergriffen, was sich darbot. Ihre Arbeit ist eigentümliche und besondere Wege gegangen, und Sie haben nicht sich gesträubt, das schcinbar Widerstrebende in den Kreis derselben zu ziehen, wenn es eine gute Frucht versprach. « Es entschied für Springer aber nicht allein der Erfolg; die für das Werk von Jeremias Gotthelf gebrachten Opfer hatten es gezeigt. So fährt Hertz dann auch fort: »Ihr Geschäft haben Sie nicht nur geliebt als die Quelle des Erwerbes, welches die Ihrigen, Weib und Kind, ernähren sollte. Sie haben Ihren Beruf geliebt seiner selbst willen und fleißig mitgearbeitet an der eigentümlichen Organisation desselben.«

Die Vielfalt gleichzeitiger und aufeinanderfolgender verlegerischer Aktivitäten macht es dem Chronisten nicht leicht, einen 
roten Faden in Springers verlegerischer Arbeit auszumachen. Seine vielseitigen Interessen ließen ihn vielerlei scheinbar nicht Zusammenhängendes in scinem Verlag vereinen. So trugen manche seiner verlegerischen Unternehmungen eine recht persönliche, zufällige Note. Erst in den 1860er Jahren wird die Absicht deutlich, der praktischen Literatur eine bevorzugte Stelle in seinem Verlag einzuräumen. Wenn Springer $1870 \mathrm{dem}$ verstorbenen Braunschweiger Kollegen Eduard Vieweg in einer Gedenkrede nachrühmte, dieser habe früher als andere erkannt, »daß in der Literatur zunächst die Naturwissenschaften blühen würden « [FrommanN: 94], so war er selbst dieser Einsicht erst in seinen letzten Lebensjahren mit größerer Konsequenz gefolgt. Es gab zwar in seinem Verlag schon vereinzelt Bücher z. B. für Chemiker und Ingenieure, doch der systematische Ausbau dieser Programme begann erst unter seinen Söhnen.

Schon in seinen ersten Berufsjahren hatte sich Springer berufsständischen und - nach seiner Etablierung - auch Problemen des Gemeinwesens zugewandt. Diesen Aufgaben widmete er sich mit einem wesentlichen Teil seiner Arbeitskraft. »Wenn die Sorge um die Existenz des Einzelnen und seine Familie beseitigt, « sagte er in diesen Jahren gelegentlich zu einem Berufskollegen, »dann tritt an ihn die Verpflichtung heran, seine Kräfte dem allgemeinen Wohle zuzuwenden« [KAISER: 2313].

Seine Frau hatte zchn Kinder geboren, von denen sieben schon in früher Jugend dem $>$ Würgengel $<$, der Diphterie, zum Opfer gefallen waren. Der älteste Sohn Ferdinand war schon seit 1871 mit Erfolg im Verlag des Vaters tätig; der jüngere trat, ohne daß dies zu des Vaters Lebzeiten erörtert worden war, bald an dessen Seite (s.S. 82).

Anfang 1877 trat bei Springer ein schon fünf Jahre zuvor bemerktes Magenleiden stärker in Erscheinung. Nur durch die Autorität seines Arztes konnte er bewogen werden, einer wichtigen Sitzung des Stadtrates fernzubleiben, und obwohl man dort von seiner Krankheit wußte, wurde er in der Sitzung vom 4.1.1877 erneut zum Stellvertreter des Vorsitzenden gewählt. Springer stand vor der Vollendung seines 60. Lebensjahres, und man gab ihm noch einige fruchtbare Jahre.

Von einer für die ersten Apriltage in Aussicht genommenen Badereise erhoffte sich die Familie Linderung oder gar Genesung. Am 15. April hatte Springer seine Messeabrechnungen vorbereitet und einen Brief an seinen Leipziger Kommissionär Friedrich Volckmar geschrieben. Es war sein letzter. Zwei Tage später, am 17. April wurde er dann von den schweren Leiden

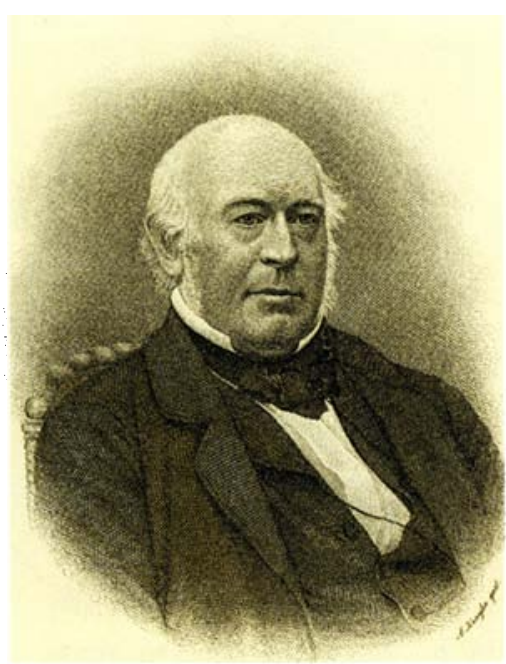

72: Der Verleger Hans Heinrich Eduard Vieweg (1796-1869) hatte sich schon friih den Naturwissenschaften zugewandt. Fr wurde, wie Springer in seinem Nachruf hervorhob, auf diesem Feld sehr erfolgreich. 


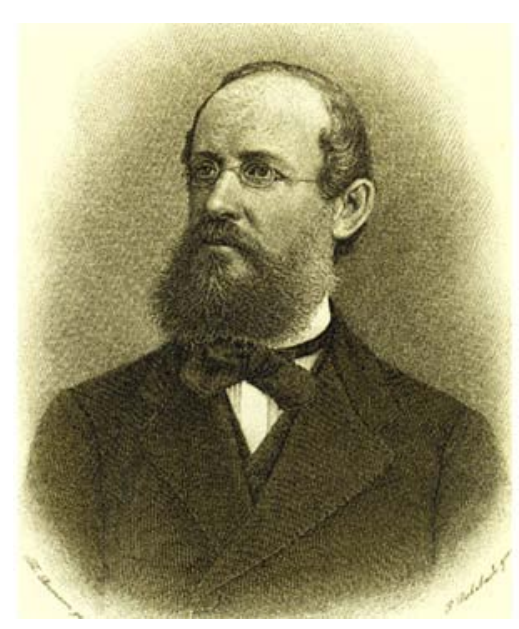

73: Hermann Kaiser (1820-1881) hatte 1851 die Schrödersche Buchhandlung Unter den Linden übernommen. Nach dem Verkauf des eigenen Sortiments informierte sich Julius Springer bei ihm und bei seinem Freund Wilhelm Hertz gern äbor Neuerscheinungen des Buchmarkts. 1877 schrieb Kaiser den Nachruf auf Springer für das Börsenblatt.

74: Julius Springer, Aufnahme aus seinen letzten Lebensjahren.

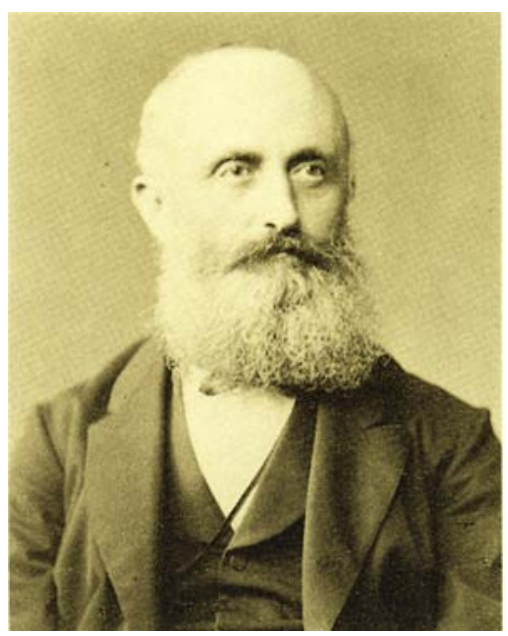

der letzten Monate erlöst. Scine letzte Ruhe fand er auf dem Friedhof der Sophien-Gemeinde, ${ }^{20}$ deren Vorstand er jahrelang angehört hatte.

Der Börsenverein der Deutschen Buchhändler ehrte ihn 1873 , indem cr sein Porträt im Festsaal des Buchhändlerhauses aufhängte. ${ }^{21}$ Außer seinem Freund Moritz Veit war Springer der einzige Buchhändler jüdischer Herkunft, der dieses höchste Amt in der Berufsorganisation bekleidet hat.

Die Abkunft seiner Familie aus dem deutschen Judentum war für Springers Arbeit ohne erkennbare Bedeutung. Als Verleger hatte er wohl Schriften zur Emanzipation der Juden herausgebracht, doch diese standen neben solchen, die der politischen und geistlichen Emanzipation galten. Die Wurzeln der Familic werden weder in den Erinnerungen von Marie Springer noch in denen von Fritz Springer auch nur angedeutet. Man fühlte sich ohne Einschränkung als Deutsche und als Christen, deren Vorfahren dem mosaischen Glauben verbunden gewesen waren.

Es gibt keine bessere Würdigung der Persönlichkeit Springers als die seines Sohnes Ferdinand zur Wiederkehr des 75. Geburtstags am 10.5.1892, als zugleich das fünfzigjährige Bestehen des Verlags begangen wurde:

Ich darf Ihnen meinen Vater vorstellen als einen Mann von höchster Energie, begabt mit scharfem, kritischem Verstande, der in der Lösung schwieriger juridischer Fragen cine willkommene Abwechselung erblickte, mit ciner fast unbegrenzten Arbeitskraft und Arbeitsfreudigkeit, der nach der Erledigung seiner recht bedeutenden und mannigfachen Korrespondenz sich auch noch gern an die rein mechanischen buchhändlerischen Arbeiten machte, dabei heiteren und fröhlichen Sinnes, voll warmen und herzlichen Mitgefühls für die Leiden und Sorgen seiner Mitmenschen, stets bereit, einzugehen auf das, was den anderen interessierte, zu helfen mit Rat und Tat; lebhaft und frisch von früh bis spät - ein Mann, dem sein lieber Freund Hertz vor 25 Jahren bei der Feicr des 25jährigen Geschäftsjubiläums als Sinnspruch dic schöne Devise des Prinzen von Wales empfahl: > Ich dien!< Von Jugend auf war er voll dankbarer Anerkennung für alles Gute, was ihm zuteil wurde für sein Vorwärtskommen, und wenn ihm auch schwere Sorgen im Geschäft und in der Familie - sieben Kinder sah er vor sich sterben nicht erspart blieben, so richtete er sich doch bald wieder auf an dem Guten, das ihm das Geschick erhielt und brachte. Und so haben wir ihm auf seinen Grabstein den Spruch gesetzt, mit dem ein Schweizer Freund ihn nach seinem Schciden kennzeichnete: Gott war ihm gnädig, und er ihm dankbar [Mfnz (2): 185]. 